\title{
Delivering Clinically on Our Knowledge of Oxytocin and Sensory Stimulation: The Potential of Infant Carrying in Primary Prevention
}

Henrik Norholt*

SomAffect - The Somatosensory \& Affective Neuroscience Group, Liverpool, United Kingdom

Oxytocin (OT) is one of the most intensively researched neuropeptides during the three past decades. In benign social contexts, OT exerts a range of desirable socioemotional, stress-reducing, and immunoregulatory effects in mammals and humans and influences mammalian parenting. Consequentially, research in potential pharmacological applications of OT toward human social deficits/disorders and physical illness has increased substantially. Regrettably, the results from the administration of exogenous OT are still relatively inconclusive. Research in rodent maternal developmental programming has demonstrated the susceptibility of offspring endogenous OT systems to maternal somatosensory stimulation, with consequences for behavioral, epigenetic, cognitive, and neurological outcomes. A translation of this animal research into practically feasible human parenting recommendations has yet to happen, despite the significant prevention potential implied by the maternal developmental programming research. Extended physical contact with full-term healthy infants in the months following birth (infant carrying) might constitute the human equivalent of those specific rodent maternal behaviors, found to positively influence emerging OT systems. Findings from both OT and maternal programming research parallel those found for infants exposed to such extended parental physical contact, whether through skin-to-skin contact or infant carrying. Clinical support of parents to engage in extended physical contact represents a feasible intervention to create optimum conditions for the development of infant OT systems, with potential beneficial long-term health effects.

Keywords: oxytocin, skin-to-skin contact, infant carrying, intervention, prevention, affective touch, caregiving

\section{HIGHLIGHTS}

- Oxytocin is implicated in positive physiological and psychological adaptations, with significant consequences for lifelong health.

- Oxytocin systems are shaped by early bidirectional parent-infant somatosensory stimulation.

- In oxytocin research, concluding remarks frequently highlight the vital necessity to translate findings to parenting practices.

- No medical guidelines exist to support optimum early development of oxytocin systems in humans.

- Increasing clinical support for parental full-term infant carrying/skin-to-skin contact constitutes a promising avenue to influence oxytocin systems.

Abbreviations: EPIC, extended parent infant contact; LG-ABN, licking and grooming and arched back nursing; OT, oxytocin; OTA, oxytocin antagonist; OTR, oxytocin receptors; PND, postnatal days; SSC, skin-to-skin contact; VP, vasopressin. 


\section{INTRODUCTION}

In the past decades, two related research domains have been the subject of intense exploration: the neuropeptide oxytocin (OT) and rodent maternal behavioral programming of offspring neurological and behavioral development (Meaney, 2001; Buschdorf and Meaney, 2015; Insel, 2016). OT is implicated in the regulation of maternal caregiving as well as socioemotional and physiological development and health (Pedersen and Boccia, 2002; Clodi et al., 2008; Insel, 2010; Rilling and Young, 2014; Kim and Strathearn, 2016; Carter, 2017; Jones et al., 2017; Ding et al., 2019; Strathearn et al., 2019; Buemann and Uvnäs-Moberg, 2020).

In healthy human subjects, employing intranasal OT administration have shown anxiolytic effects (Heinrichs et al., 2003), enhanced recognition of emotional facial expressions (Kirsch et al., 2005; Bartz et al., 2010; Hurlemann et al., 2010; Marsh et al., 2010), increased interpersonal trust, especially among in-group members (Kosfeld et al., 2005; De Dreu et al., 2010), and elevated empathic concern for conspecifics (MacDonald and MacDonald, 2010).

These findings have sparked considerable research interest in applying OT administration to reduce or ameliorate mental disorders, including autism (Meyer-Lindenberg et al., 2011; Geng et al., 2018), depression (MacDonald et al., 2013; Kim et al., 2014), anxiety (Jones et al., 2017), social phobia, schizophrenia (Jarskog et al., 2017), insecure attachment (Buchheim et al., 2009), and addiction (Pedersen, 2017). At this stage, the most robust positive outcomes have been demonstrated for alcohol addiction (Pedersen et al., 2013; Pedersen, 2017) and autism (Hollander et al., 2003, 2007; Guastella et al., 2010; Tauber et al., 2011; Aoki et al., 2014; Watanabe et al., 2015; Yamasue, 2016; Higashida et al., 2019).

High doses of OT administration (80 IU/day) over several weeks have significant positive effects on schizophrenia (Zheng et al., 2019). Similarly, repeated intranasal oxytocin administration early posttrauma reduces subsequent PTSD symptom development in recently trauma-exposed emergency department patients with high acute PTSD symptoms (Frijling, 2017).

In non-clinical mothers, OT infusion during labor or following planned cesarian induced positive personality adaptations (Jonas et al., 2008; Velandia, 2012).

Relevant to the scope of the present article-primary prevention across both psychological and physiological domains-OT administration has been shown to induce weigth loss in humans and improve control of energy intake (Lawson et al., 2020) and may also offer potential for improved cardiovascular health through improved immune system functioning (Buemann and Uvnäs-Moberg, 2020).

For some domains, such as postpartum maternal depression and its interaction with the quality of parental caregiving, current effects of OT administration are equivocal (Scantamburlo et al., 2015; Mah, 2016; De Cagna et al., 2019).

The ambiguous outcomes of OT administration in relation to some of social disorders are in part ascribed to an enhanced "social salience effect" whereby OT increases the salience of both positive or negative social stimuli, resulting in increased prosocial behavior in positive environments, but producing defensive and, ostensibly, "antisocial behavior" in negative (competitive or potentially threatening) environments, which, however, when the behavior is viewed contextually, represents an adaptive response to social unsafe or provoking cues (Bartz et al., 2011; Bakermans-Kranenburg et al., 2012; BakermansKranenburg et al., 2013; Tabak, 2013; Ne'eman et al., 2016). Although OT has been mostly linked to prosocial behavior, it also acts a "boundary setting" hormone, influencing, e.g., maternal aggression toward intruders, experimentally placed in the maternal cage with the pups present (Bosch, 2013). For example, among high-anxiety rodent dams, the levels of intracerebral release of OT correlates with maternal aggression toward a virgin intruder (Bosch et al., 2005), and in low-anxiety strains, synthetic OT infusion in the paraventricular nucleus through retrodialysis increases maternal intruder-directed aggression (Bosch and Neumann, 2012). Attachment status/caregiving history and genetic composition is also implicated in differential outcomes of OT administration (Macdonald, 2012; Riem et al., 2013; Feldman and Bakermans-Kranenburg, 2017). Much of the OT administration research has been based on singledose treatments, whereas many of the conditions attempted to be treated are considered to be of a permanent or long-lasting nature, necessitating long-term treatments-for a review of chronic OT administration, see Horta et al. (2020). Furthermore, as evidenced by animal research, the differential effects of OT in different species is partially mediated by differential species-specific distributions of OT receptors (Insel, 2010). Exogenously administered OT reaches very different (peripheral) OT receptor sites, compared to endogenously released OT (activated through, e.g., somatosensory stimulation), in part because exogenously administered OT may not readily cross the blood-brain barrier (Leng and Ludwig, 2016; Uvnäs Moberg et al., 2019). Additionally, more work is required to establish relevant dosages of OT (Insel, 2016; Leng and Ludwig, 2016).

However, there are other pathways than pharmacological remedies for the stimulation of oxytocinergic mechanisms. Several veteran OT researchers have highlighted the early life period as one of great developmental plasticity for OT systems, calling for the translation of OT animal research to early human interventions, but regrettably, so far, there has been few concrete proposals regarding the potential nature of such an intervention (Francis et al., 1999; Pedersen and Boccia, 2002; Pedersen, 2004; Carter et al., 2009; Hammock, 2015), with Champagne (2008) and Feldman et al. (2014) as notable exceptions.

One of the salient intersections of research in OT systems functioning and rodent maternal programming, respectively, is the effects of non-noxious tactile stimulation (Francis et al., 2000; Uvnäs-Moberg et al., 2014), the latter requiring no medical involvement. The purpose of this article is to investigate the potential translation of the combined OTrelated tactile stimulation and maternal programming research into primary prevention. Primary prevention aims to prevent disease before it occurs by altering behaviors that can lead to disease or injury and increasing resistance to disease or trauma/injury should exposure occur (Institute for Health 
\& Work, 2015). Given the premise that suboptimum or dysfunctional OT functioning is implicated in a range of mental and physical illnesses (Strathearn, 2011; McQuaid et al., 2014; Kim, 2015; Wang et al., 2015; Colonnello et al., 2017), the essential prevention question becomes whether there may be ways to universally support an optimum development of the OT system.

One potential candidate for such primary intervention involves the practice of clinically recommended and supported extended parent-infant physical contact in the first months (EPIC), following birth at term (Norholt, 2020). Such extended parent-infant physical contact can be obtained through skin-toskin ventral-ventral contact (Bystrova et al., 2003, 2009; Bigelow and Power, 2012) or through infant carrying with both caregiver and infant clothed, whether ventral-ventral (colloquially known in Western cultures as "babywearing") (Williams and Turner, 2020), lateral-ventral ("hip-carrying"), or dorsal-ventral ("backcarrying”) (Graham et al., 2015).

It would appear obvious to include in the argumentation for such an intervention the full range of studies, which have sought to correlate plasma or saliva levels of OT to human behavioral phenotypes, especially in relation to both maternal and paternal caregiving. However, it is not clear at this stage whether such peripherally derived measures reliably reflect central nervous system concentrations of OT (Altemus et al., 2004; Kagerbauer et al., 2013; Carson et al., 2015). The interpretation and comparability between some of the human studies are also hampered by concerns regarding the validity of widely used commercially available immunoassays, which quantify peripheral OT concentrations in plasma and saliva (Horvat-Gordon et al., 2005; Szeto et al., 2011; McCullough et al., 2013; MacLean et al., 2019). One complication when comparing measurements of plasma and saliva OT levels arises from the finding that saliva OT appears to be a weak correlate for plasma OT (Quintana et al., 2018).

Furthermore, the two dominant approaches to measuring OT in plasma, radioimmunoassay and enzyme immunoassay, result in OT levels that are 100-fold different and, even more bewildering, are not correlated (Szeto et al., 2011; McCullough et al., 2013). Radioimmunoassays detect the intact OT hormone, whereas enzyme immunoassays may have less specific binding properties, which consequently detect both OT fragments as well as the principal OT hormone, leading to higher OT values (McCullough et al., 2013; Uvnäs Moberg et al., 2019). Our understanding and measurement of the impact of OT on physiological and behavioral systems are furthermore complicated by the possibility that oxytocin may be a principial hormone, exerting its effects in part through larger precursor OT molecules or converted active OT fragments with more specific effect profiles, the latter potentially binding to other receptors (such as alpha-2-adrenoreceptors) than the classical OTR (Uvnäs Moberg et al., 2019). For the most recent insights into validation of OT measurements, please refer to MacLean et al. (2019), but consider also Uvnäs Moberg et al. (2019) work on OT fragments. For reviews of OT in human parenting (e.g., Feldman, 2016; Feldman and Bakermans-Kranenburg, 2017).
Thus, the article will provide a brief summary of relevant OT research, with an emphasis of the effects of non-noxious tactile stimulation as well as the rodent maternal developmental programming research, which is centered on variations in maternal tactile stimulation-pupdirected licking and grooming and maternal skin-to-skin contact. The modalities and effects of extended parentinfant contact are described and discussed in relation to OT sensory stimulation and maternal developmental programming research. Clinical and policy implications are elaborated.

\section{GENERAL ASPECTS OF OT}

OT and the closely related peptide hormone vasopression (VP) are among the oldest mammalian hormones and are considered to have been central to human evolution (Robinson et al., 2019). Here, the description is restricted to OT (see, e.g., Carter, 2017 for a description of OT and VP dynamics). OT dynamically modulates the autonomic nervous system, affects vagal and immune system functioning, and exert pervasive adaptive functions on social behavior, which again predicts both emotional and physical health (Puig et al., 2013; Carter, 2014).

OT is a neuropeptide consisting of nine amino acids, produced in two nuclei within the hypothalamus, i.e., the paraventricular nucleus and the supraoptic nucleus. Within these two cell groups, OT is produced in two types of cells: the magnocellular neurons and the parvocellular neurons. OT has a dual function as both a hormone and as a neurotransmitter. Its hormonal effects are exerted via magnocellular neurons within the paraventricular nucleus and the supraoptic nucleus, which project to the neurohypophysis wherefrom oxytocin is released into the circulation, where it mediates the classically known OT effects on uterine contraction during labor and milk ejection during breastfeeding. However, the magnocellular neurons are furthermore provided with axon collaterals, which reach other regulatory parts of the brain, including the frontal cortex, the amygdala, and the anterior pituitary, where OT acts as a neurotransmitter. The parvocellular OT neurons emanating from the paraventricular nucleus also contribute to the neurotransmitter function of OT through their projections to many different cortical, limbic, and brainstem areas of the brain (Uvnäs-Moberg, 2015). Under conditions of intense stimulation of OT secretion, where OT is released not only from the axons of OT-producing neurons but also from the cell body and dendrites, OT can also exert its effects through diffusion to nearby and even distant parts of the brain to which no OT neurons project but which contain OT receptors (Ludwig and Leng, 2006). Such intense stimulation may furthermore induce temporary morphological changes in the OT-producing areas in the hypothalamus, causing surrounding supporting glia cells to withdraw, inducing functional changes in that the OT-producing cells gradually synchronize their electrical activity, leading to their releasing of electrical bursts, which induce pulses of OT into the circulation, as 
seen during labor and breastfeeding (Hatton et al., 1984; Theodosis, 2002).

\section{Oxytocin Production in Extrahypothalamus Sites}

Production of OT is not restricted to the hypothalamus but has been found to also occur in the uterus, ovaries, amniotic fluid, placenta, heart, blood vessels, gastrointestinal tract, testes, kidneys, and thymus, where they exert local (paracrine) effects (Gimpl and Fahrenholz, 2001).

\section{OT Receptors}

OT exerts its functions by binding to identical OT receptors (OTRs), present in both the brain and in the peripheral organs (uterus, mammary glands, kidneys, stomach, heart, blood vessels). Blocking OT receptors of the uterine kind with antagonists do not nullify all effects induced by OT, so additional as yet unidentified OT receptors may also exist. Furthermore, OT elongated preoxytocin molecules (Amico and Hempel, 1990; Green et al., 2001) as well as degradation products can also produce specific effects through binding to such unidentified OT receptors or by binding to opioid receptors and alpha-2-adrenoreceptors (Uvnäs-Moberg, 2015; Uvnäs Moberg et al., 2019).

\section{Genetic and Epigenetic Factors}

The OT network, consisting of both OTergic neurons and OTR, is capable of undergoing dynamic changes, not least in the early stages of life, in an intricate interplay of the caregiving environment and genetic susceptibility to the caregiving environment (Toepfer et al., 2017).

\section{NON-NOXIOUS TACTILE STIMULATION AND OT IN RODENTS AND THE IMPLICATION OF THE RESEARCH FOR HUMANS}

\section{OT Release in Response to Non-noxious Somatosensory Stimulation}

Some of the earliest indicators of oxytocin release in response to stimulation of sensory nerves originating in the skin spring from rodent research, conducted by the oxytocin research pioneer, Kerstin Uvnas-Moberg. When anesthetized adult rats were exposed to electric stimulation of the sciatic or vagal nerves or received gentle stroking on their backs, plasma OT levels rose by $30-184 \%$ or $181 \%$, respectively (Stock and Uvnäs-Moberg, 1988). Employing either vibration, warm temperature, or electroacupuncture to male anesthetized rats similarly increased plasma and cerebrospinal fluid OT levels (Uvnäs-Moberg et al., 1993). In humans, massage-like hand movements applied by newborn babies to their mother's breast increased maternal plasma oxytocin levels (Matthiesen et al., 2001). Similarly, 15 min of moderate-pressure Swedish massage significantly increased plasma oxytocin levels in both men and women (Morhenn et al., 2012).

\section{Effects of Non-noxious Sensory Stimulation}

Non-noxious sensory stimulation directed toward somatosensory nerves in either conscious or unconscious rodents acts through differentiated brain pathways to, respectively, reduce sympathetic nervous system activity as well as to increase parasympathetic nervous system activity. These physiological changes give rise to a range of effects, such as increased functioning of the gastrointestinal tract (Holst et al., 2005), increased sociability (Wei et al., 2013), increased pain threshold (Agren et al., 1995), as well as significant antistress effects (decrease in blood pressure and cortisol levels) (Araki et al., 1984; Lund et al., 1999; Wei et al., 2013). Interestingly, the effects of intercerebroventricular OT administration (which bypasses the blood-brain barrier) greatly resembles the effects induced by non-noxious sensory stimulation (Uvnäs-Moberg, 2015). Considering the abovementioned findings that OT is released in response to such stimulation, it is likely that OT is involved in mediating the effects described for non-noxious sensory stimulation. That OT mechanisms are involved is supported by the finding that the elevated pain threshold induced by ventral stroking in rodents is thwarted by the administration of an OT antagonist prior to the tactile stimulation (Uvnäs-Moberg et al., 1993; Agren et al., 1995).

In sum, non-noxious somatosensory stimulation in rodents and humans and its resultant contextually adapted OT response appear to reduce sympathetic nervous system activity as well as activate the parasympathetic nervous system, enabling a state of growth and relaxation or of calm and connectedness, a state that is optimum for both a growing infant and for its caregiving parents, combining the twin goals of supporting infant physical growth/state organization as well as the development a mutual emotional connection (Uvnäs-Moberg et al., 2005; Welch and Ludwig, 2017). In the following section, we will explore studies of maternal tactile stimulation and/or OT administration in the postnatal period and their potential influence on offspring state regulation and biology as well as the offspring own parenting behaviors.

\section{RODENT MATERNAL TACTILE STIMULATION AND OFFSPRING DEVELOPMENTAL OUTCOMES IN RELATION TO OT}

OT has long been known to be implicated in basic female reproductive events, such as birth (Dale, 1906, 1909) and breastfeeding (Ott and Scott, 1910). That OT could have a role in modulating social behavior during the transition to maternal behavior in the goat was first proposed by Klopfer and Klopfer (1968) and Klopfer (1971). Pedersen and Prange (1979) and Pedersen et al. (1982) tested that hypothesis by intercerebroventricular injections of OT in virgin rats, which, in an estrogen-dependent manner, stimulated the onset of full maternal behavior.

Research in the behavioral, neurological, and epigenetic outcomes of maternal tactile stimulation has been made possible 
through the serendipitous observation that rodent mothers within the same species will naturally vary in the amounts of contact, licking and grooming (LG), and arched back nursing $(\mathrm{ABN})$ they direct at their pups during lactation, with significant positive correlations to adult blood pressure (Myers et al., 1989a,b).

To test the developmental and potential non-genomic outcomes of these natural variations in maternal caregiving, Francis et al. (1999) employed cross-fostering as well as an environmental manipulation imposed during early development, which alters maternal behavior, especially maternal LG-ABN of pups. They were able to convincingly demonstrate that variations LG-ABN serve as the basis for a non-genomic transmission of both maternal behavior and stress reactivity.

A major breakthrough in demonstrating how OT systems are linked to the specific maternal behavioral component of pup-directed licking and grooming and arched back nursing was achieved with subsequent studies showing that lactating females characterized as Low LG-ABN during the first week postpartum have decreased levels of OTR binding in the medial preoptic area of the hypothalamus compared to high LG-ABN dams (Champagne et al., 2001; Francis et al., 2000, 2002), as do their offspring. Furthermore, a reduction in pup-directed LG-ABN among high LG-ABN dams can be achieved through central infusion of a selective OTA, in contrast to insignificant effects in low LG-ABN dams (Champagne et al., 2001). Pedersen and Boccia (2002) replicated this finding and also observed an increase in maternal self-grooming, following infusion of an OTA, leading to the conclusion that one of the functions of OT during lactation may be to shift maternal oral grooming away from themselves and instead direct it at the offspring. The expression of estrogen receptor in the medial preoptic area has been shown to be implicated in the expression of OTR and is furthermore susceptible to caregiving environments, as demonstrated through cross-fostering studies (Champagne et al., 2006). As for developmental outcomes, the level of maternal LG-ABN has been found to correlate positively with offspring maternal behavior (specifically LG-ABN behavior) during adulthood, behavioral and endocrine responsiveness to stress, emotionality, performance in tests of spatial learning and object recognition, and glucocorticoid receptor genetic expression in the hippocampus (Liu et al., 1997, 2000; Francis et al., 1999; Caldji et al., 2000).

Pedersen and Boccia (2002) have provided longitudinal evidence that maternal care regulates OT activity in pups, which in turn influences the development of OTR and the development of maternal care when the experimental animals become mothers themselves. Oxytocin receptor concentrations in areas of the adult brain where oxytocin stimulates maternal behavior or diminishes anxiety and adrenal axis responses to acute stress have been shown to be positively related to LG-ABN received during infancy. In a separate study on postnatal days 2-10, pups (F1) were treated with either subcutaneous administration of OT, an OTA, or saline vehicle. At 3-4 months of age, the F1 dams were mated and LG-ABN frequency measured during PND 2 and 5. Through videotaping the maternal behavior of the F0 rearing dams, the outcomes were controlled for variability in maternal caregiving received during the infancy of the F1 dams. Compared to F1 dams treated with saline vehicle, LG$\mathrm{ABN}$ frequency was significantly higher in F1 dams that received postnatal OT and significantly lower in F1 dams treated with OTA (Pedersen and Boccia, 2002).

Furthermore, attesting to the long-term effects of early OT exposure, rats given subcutaneous OT injections or exposed to brief stroking episodes on the ventral side of the abdomen once a day in the postnatal period result in adult decreased blood pressure (Holst et al., 2002) and corticosterone levels (Sohlström et al., 2000) as well as increased adult nociceptive thresholds and increased functioning of central alpha-2-adrenoreceptors (DíazCabiale et al., 2004), the latter with implications for improved stress regulation (Uvnäs-Moberg et al., 2014).

Early studies of the development of OTR expression in rodents indicate that they arise in several brain sites at PND 5 and then gradually increase in density until PND 10-14, to then disappear in most sites at the time of weaning (Shapiro and Insel, 1989; Tribollet et al., 1991). The adult pattern of OTR expression begins to emerge during puberty, which is the other highly plastic period (Gimpl and Fahrenholz, 2001). One of the few brain structures in which oxytocin receptors appear during the early phase and then persist into adulthood is the amygdala (Pedersen and Boccia, 2002). This early expression of OTR in central brain regions coincides with the period where maternal LG-ABN exerts its strongest effects on stress responses and maternal behavior (Meaney et al., 1996). Confirming the existence of this sensitive period, studies employing an environmental manipulation known to increase maternal pupdirected licking and grooming (handling, see Meaney et al., 1996; Lee and Williams, 1974) demonstrate that such manipulation is effective at attenuating stress responses if experienced during the first postnatal week but less so or not at all effective if the handling is experienced exclusively during the second and third postnatal weeks, respectively (Levine and Lewis, 1959; Meaney and Aitken, 1985). Providing an even more fine-grained analysis of the developmental timing of the effects of maternal care on the offspring's maternal sensitivity, cross-fostering high LG-ABN and low LG-ABN pups at PND 6 produces a shift in maternal sensitivity when the experimental pups become dams themselves so as to correspond to the rearing conditions of the adoptive dam. However, cross-fostering at PND 10 does not demonstrate an effect on maternal sensitivity (Peña et al., 2013).

Through fine-grained behavioral analyses of three main maternal behaviors, which constitute the LG-ABN complex (licking and grooming; simple physical contact lasting $30 \mathrm{~s}$ or more; skin-to-skin contact involving large areas of the pup's body lasting $1 \mathrm{~m}$ or more) directed at individual 14 PND pups, Kojima et al. (2012) have shown that, of these three main behaviors, only skin-to-skin contact correlated with hypothalamus OT, but not with peripherally measured plasma OT. Interestingly, it is the thermotactile component of skin-to-skin contact-i.e., the mother reliably providing cutaneous warmth-which appears to potentiate pup OT concentrations as well as facilitate their acquisition of a filial huddling preference. Neither suckling, milk reward, maternal licking, nor mechanotactile stimulation such as stroking appear to affect the acquisition of a filial huddling 
preference at that particular stage of development (approx. PND 14) (Alberts and May, 1984; Kojima and Alberts, 2009, 2011; Kojima et al., 2012).

These findings, however, do not preclude that the specific licking and grooming behavioral component may influence emerging OT systems during PND 1-13, owing to the extremely dynamic development of OT systems and the large changes in levels and types of maternal care during the preweaning period. In fact, partial reversal of the maternal caregiving deficits normally associated with being raised without a mother was achieved through experimenter-provided licking and groominglike stimuli during PND 4-20 only (Gonzalez et al., 2001; Lovic and Fleming, 2004).

From these combined findings, we can conclude that rodent pup OT systems are amenable to maternal sensory stimulation, notably licking and grooming and skin-to-skin contact and its concomitant provision of cutaneous warmth. The early shaping of OT systems appears to predict both the offspring's own maternal behavior as well as epigenetic, endocrine, cognitive, and stress-regulatory outcomes.

\section{EXTENDED PARENT-INFANT PHYSICAL CONTACT}

We now turn to our analysis of a potential candidate for the clinical application of the extant findings of the OT research summarized above-extended parent-infant physical contact (EPIC), as described in section "Introduction." We will address the following questions: (1) Does EPIC involve the human equivalents of the specific maternal caregiving behaviors found to influence OT systems in rodents? (2) Has EPIC been found to influence OT levels in parents and full-term infants? (3) Does EPIC positively influence those particular outcome domains that have been documented following exogenous release of OT or externally administered OT? (4) Does the support of universal EPIC among caregivers of healthy full-term infants constitute a clinically relevant and scalable intervention?

\section{Does EPIC Involve the Human Equivalents of the Specific Parental Caregiving Behaviors Found to Influence OT Systems in Rodents?}

Whereas caution should be exerted in translating findings from animal research to humans (Perel et al., 2007), the extant findings from both animal and human research on the links between non-noxious tactile or other somatosensory stimulation and an increase in central or peripheral OT levels suggest that similar mechanisms may be at play (Stock and Uvnäs-Moberg, 1988; Matthiesen et al., 2001; Morhenn et al., 2012). So far, we have evidence from animal studies that maternal pup-directed licking and grooming as well as maternal ventral skin-to-skin contact lasting more than $1 \mathrm{~min}$ per bout influence offspring OT systems (Francis et al., 2000; Champagne et al., 2001; Kojima et al., 2012).

We begin our analysis with examining parallels of extended bouts of rodent skin-to-skin contact to large parts of the pups' body (Kojima et al., 2012) with the specific somatosensory stimulation associated with EPIC. As briefly described in section "Introduction," EPIC covers a range of relatively similar practices, which all have in common that the infant is placed ventrally toward the caregiver for prolonged periods, usually lasting significantly longer than $1 \mathrm{~min}$ per bout of carrying (Anisfeld et al., 1990; Pisacane et al., 2012; Williams and Turner, 2020). Such ventral-ventral contact exerts a static pressure and is likely to activate specific C-fibers, which innervate the breasts and the chest and which are connected to the vagal nuclei, which are possibly in functional contact with cells producing OT in the hypothalamus (Eriksson et al., 1996; Nelson et al., 1998). However, not only non-myelinated C-fibers are activated, but myelinated sensory nerve fibers also play a role in inducing antistress effects, in which OT is likely to play a role (Sato and Schmidt, 1987). Indeed, ventral-ventral skin-to-skin contact have been shown to increase both parental and infant salivary OT levels and to decrease salivary cortisol levels, inducing less anxiety and more synchronous and responsive in parents (Cong et al., 2015; Vittner et al., 2018).

Furthermore, similar to the mechanisms uncovered in rodents (Alberts and May, 1984; Kojima and Alberts, 2009, 2011; Kojima et al., 2012; Meyer and Alberts, 2016), maternal provision of cutaneous warmth during ventral-ventral contract activates cutaneous nerves in the infant, leading to release of OT in the infant, which decreases sympathetic nervous system activity, which in turn reduce infant vasoconstriction, resulting in higher infant skin temperature (Bystrova et al., 2003, 2007; Moberg et al., 2020). Detailed analyses of maternal chest temperature following birth demonstrate both a higher temperature than that of the infant as well as higher variability in a pulsatile pattern when in skin-to-skin contact. This pulsatile pattern is highly adapted to stimulate the increase in infant temperature, as a varying temperature activates the infant cutaneous sensory nerves more effectively than a stable temperature, leading to a synchronization of mother and infant temperatures (Bystrova et al., 2003).

As for the specific mechanotactile maternal behavior of rodent licking and grooming, a human equivalent is considered to be maternal gentle stroking of the infant, at the speed and pressure level, which has been shown to activate a class of touch sensitive nerve fibers named C-Tactile afferents, inducing epigenetic and stress-regulatory effects similar to those found in rodent licking and grooming studies (Murgatroyd et al., 2015; Sharp et al., 2015; Pickles et al., 2017). Furthermore, the effects of this type of affectionate touch has been shown to mirror more generally those that have been reported following endogenous release and exogenous administration of oxytocin and are likely partially mediated by C-Tactile afferents, as reviewed by Walker et al. (2017). Although this is so far not quantitively examined, casual observations and video documentation (Bigelow and Gillis, 2010) of parents engaging in EPIC demonstrate a proclivity of parents to also perform-concurrently-infantdirected affectionate touch in the form of light stroking.

In conclusion, EPIC involves the human functional equivalents of the specific somatosensory stimuli that have been shown in rodent research to influence offspring OT systems, especially ventral-ventral skin-to-skin contact, providing 
cutaneous warmth, and may also include parental gentle stroking, considered the functional equivalent of rodent licking and grooming. There is still a large research effort ahead to first of all investigate the many potential configurations of combinations of concurrent ventral contact and maternal stroking among human caregivers, and second, to tease out the relative contributions of these two discrete caregiving behaviors to the development of infant OT systems during the period of the infant life span where EPIC is normally conducted.

\section{Has EPIC Been Found to Influence OT Levels in Parents and Full-Term Infants?}

So far, no studies have been conducted on full-term infants and their caregivers. However, Vittner et al. (2018), employing the methodology developed by Sue Carter et al. (2007), measured salivary OT and cortisol levels in stable preterm infants and their mothers and fathers before, during, and after a session of skin-to-skin contact in the neonatal intensive care unit (NICU) environment. Salivary OT levels increased significantly during SSC for mothers, fathers, and infants. Cong et al. (2015) similarly measured parental salivary OT before, during, and after a single session of SSC and found both maternal and paternal OT levels to be significantly increased during SSC from baseline. Paternal OT continued to be maintained at a higher level after the SSC session, whereas maternal OT declined.

The question of whether EPIC influences OT levels is, however, complicated by the possibility that much of OT's effects are exerted through active fragments, which, in the case of skin-to-skin contact, exert antistress effects by acting on alpha-2adrenoreceptors, decreasing sympathetic nervous system activity. Furthermore, in contrast to maternal predominant brainlocated OT response to infant suckling, skin-to-skin contact may to a greater degree activate OT production in peripheral systems, such as the blood vessels and the gastrointestinal tract (Uvnäs Moberg et al., 2019).

\section{Does EPIC Positively Influence the Main Outcome Domains That Have Been Documented Following Endogenous Release and Externally Administered OT?}

From the literature cited in the above, three different main domains of outcomes can be defined: socioemotional, stress regulation, and maternal caregiving behavior. If EPIC is to qualify as an evidence-based clinically relevant universal intervention aimed at optimizing healthy full-term infants' developing OT systems, studies should support the effects of EPIC in these domains.

\section{EPIC and Socioemotional Outcomes}

Socioemotional outcomes, especially the capacity to engage in trustful and mutually rewarding relations as measured via, e.g., attachment security, are critical, considering the accumulation of evidence regarding the fundamental role of attachment in an extensive range of developmental outcomes (Garner et al., 2012; Thompson, 2016; Ehrlich and Cassidy, 2019). Hence, in the following, a relatively in-depth description of EPIC-related outcomes is provided.

The first controlled study of EPIC randomized low socioeconomic status (SES) status US mothers after the birth of their full-term healthy infants to receive either a plastic seat $(n=26)$ or a soft cloth structured infant carrier $(n=23)$, designed to carry the infant in ventral-ventral contact (Anisfeld et al., 1990). The participants were encouraged to make daily use of the products provided. To document actual usage, pedometers were sewn inside the soft cloth infant carriers. At 13 months of age, the strange situation protocol was administered. The strange situation is considered the gold standard for measuring infant attachment quality, dividing infants into categories of either secure or insecure attachment, with implications for the effectiveness of the infants' use of the caregiver as a secure base for exploration of the environment and as stress regulator when the infant faces threatening or ambiguous environments (Ainsworth et al., 1978; Main et al., 1985). In the plastic seat control group, $38 \%$ of the infants were classified as secure, in contrast to $83 \%$ in the infant carrying group. Among the mothers supplied with infant carriers, the subgroup categorized as high users (through the pedometer readings) had 93\% securely attached infants, in contrast to $57 \%$ in the subgroup of low/moderate users, suggesting a dose-response relation between infant carrying and positive infant attachment outcomes.

In a recent partial replication, targeting another high-risk population, Williams and Turner (2020) randomized US teenage mothers to either receive an infant carrier $(n=16, \min .1 \mathrm{~h} /$ day of infant carrying for 3 months) or high contrast baby books $(n=17)$ at 2-4 weeks postpartum. At 7 months of age, infant behaviors during the Still-Face Paradigm (Tronick et al., 1978) were coded through an algorithm derived from the Infant Global Rating Scales to determine attachment type (Murray et al., 1996; Abbott, 2016). Infants of mothers issued an infant carrier were more likely to have secure attachments and less likely to have disorganized attachments compared to infants whose mothers were issued baby books. Hours spent in an infant carrier were positively correlated with secure attachment and negatively correlated with disorganized attachment.

The effects of increasing maternal provisions of SSC during the first postpartum month has also been investigated in a Canadian study of low-risk middleclass mothers (Bigelow and Power, 2012). The experimental group $(n=28)$ was asked to engage in daily SSC and consequently held their infants for $5 \mathrm{~h}$ /day during the first postpartum week and $3 \mathrm{~h}$ /day during postpartum weeks $2-4$. A control group $(n=52)$ was established for whom no recommendations for SSC were issued, and consequentially, very little SSC was provided. At 1 week and 1, 2, and 3 months, the Still-Face Paradigm (Tronick et al., 1978) was employed to track the infants' socioemotional development. The SSC infants were found to have an accelerated socioemotional development across these measurements, both in comparison to the control group and to normative development, found in other samples. Furthermore, at the age of 3 months, the SSC infants were found to increase their non-distress vocalizations during the still-face episode compared to the interactive phases of the Still-Face Paradigm, demonstrating the SSC infants' 
bids to reengage the unresponsive mother. At that age, such unresponsive maternal behavior will usually frustrate and weaken infant social bidding. A meta-analysis suggests a link between such more eliciting behavior and positive affect during the still-face episode and infant secure attachment at 12 months (Mesman et al., 2009).

A follow-up study at child age 9 years had these Canadian children and their mothers engage in conversation about remembered emotional events in the children's lives. The conversations were assessed on the Autobiographical Emotional Events Dialogue. Those mother-child dyads, which has engaged in SSC during early infancy, demonstrated more engagement and reciprocity and had a greater likeliness of being classified as emotionally matched. These findings support that early provisions of skin-to-skin contact, which is likely to have influenced emerging OT systems, may have set the motherchild dyads on a mutually socially positive developmental course (Bigelow et al., 2018).

Corroborating the contributions of the thermotactile component of EPIC-the reliable maternal provision of cutaneous warmth-to infant OT systems and socioemotional development, SSC provided postpartum increased neonate peripheral temperatures, relative to control neonates, which were either separated or held in arms while dressed (Bystrova et al., 2003). Furthermore, the neonates' capacity to maintain high peripheral temperature through their exposure to maternal cutaneous warmth during the first postpartum days predicted their significantly improved socioemotional competencies, relative to control infants, 1 year after birth, revealing a remarkable continuation of optimum physiological regulation to the domain of psychological regulation (Bystrova et al., 2009).

\section{Stress Regulation}

There are no studies examining the effects of EPIC in full-term infants on the classical indices of stress regulation, such as cortisol reactivity. However, there are several studies that provide indirect evidence of an improved infant stress regulation through displays of more optimum state control as well as physiological and behavioral calming. For example, when carried in the arms of a briskly walking mother, infants aged $<6$ months demonstrated reduced crying, body movement, and heart rate, as well as increased heart rate variability [the latter indicative of a more optimum autonomic nervous system regulation (Porges et al., 2019)], compared to stationary holding or being placed in a cot (Esposito et al., 2013).

Similarly, 2-day-old healthy full-term infants placed separately to their mother in a cot and exposed to maternal SSC for $1 \mathrm{~h}$ in each location demonstrated an $82 \%$ decrease in quiet sleep during maternal separation in comparison to SSC, as well as a significantly greater latency to enter into quiet sleep, indicative of activation of the sympathetic nervous system (Morgan et al., 2011). Whereas there are no longitudinal data for the longterm effects on sleep organization of early SSC provision among full-term infants, a longitudinal study of premature infants exposed to maternal SSC for at least 14 days of $2 \mathrm{~h}$ /day during their NICU stay demonstrated significantly more optimum sleep organization, with more quiet sleep and quiet alert states at term
(Feldman et al., 2002). Follow-up at child age 10 years showed that the children exposed to SSC during their prematurity had a significantly greater sleep efficiency and significantly shorter bouts of nighttime awakenings, as measured through five nights, wearing an actigraph, in comparison to the children who received standard incubator care during prematurity (Feldman et al., 2014). Such findings of long-term effects of an early touchrelated intervention, which presumably influences developing OT systems, are consistent with the rodent OT research where subcutaneous OT injections or exposure to brief stroking episodes on the ventral side of the abdomen once a day in the postnatal period results in adult decreased blood pressure (Holst et al., 2002), corticosterone levels (Sohlström et al., 2000), increased adult nociceptive thresholds, and increased functioning of central alpha-2-adrenoreceptors (Díaz-Cabiale et al., 2004), the latter positively influencing stress regulation (Uvnäs-Moberg et al., 2014). Nevertheless, to fully corroborate the existence of similar mechanisms for such strong early programming effects in the more developed and physiologically stable full-term infant, longitudinal studies targeting full-term infants and their parents are required.

A study of differences between core and peripheral temperatures across the first two days of life of healthy infants born at term demonstrated how being in SSC with the mother ensures a positive neonate heat balance, whereas being placed separately in the cot results in heat loss of up to $70 \mathrm{~W} / \mathrm{m}^{2}$, which is close to what a neonate can compensate for (Fransson et al., 2005). Hence, during the first few days of life, SSC is effective in avoiding cold stress (Bystrova et al., 2003).

Infant crying is an indicator of stress, hence less crying ought to suggest an improved stress regulation. EPIC has been shown to reduce infant crying in two trials with healthy full-term infants (Hunziker and Barr, 1986; St James-Roberts et al., 2006), whereas EPIC may not be effective in alleviating colic (distress $>3 \mathrm{~h}$ /day) (Barr et al., 1991; St James-Roberts et al., 1995, 2006), suggesting that colic/unsoothable crying may have as yet understood underlying neurological causes (St James-Roberts, 2008).

\section{Maternal Caregiving}

Of the three studies that have investigated EPIC effects on infant social development two have also studied potential effects on maternal caregiving quality. When the infants in Anisfeld et al. (1990) study had reached the age of 3.5 months, 15 min film video recordings of each mother-infant dyad were made of a free-play session. Those mothers who had been issued an infant soft structured carrier at birth were found to be more contingently vocally responsive and showed a trend toward being more sensitive toward their infant's cues, state, and rhythm, as measured by the sensitivity-related scale from Crnic's system (Crnic et al., 1983), in comparison to the control group, which was issued a plastic seat. According to a logistic regression analysis, the differences in attachment outcomes were not solely due to differences in maternal responsiveness. Hence, infant carrying appeared to have an effect beyond that attributable to maternal responsiveness.

In their study of 80 middle-class mother-infant dyads, Bigelow et al. (2014) employed the Nursing Child Assessment 
Feeding Scale (NCAFS), which measure among others maternal sensitivity to infant cues well as responsivity to infant distress at each visit at 1 week and 1,2, and 3 months postpartum. They, however, found no significant differences in mother-infant interactions between SSC mothers and controls.

Considering that both of the above studies found significant differences in infant socioemotional outcomes, it would appear that maternal sensitivity-oriented measures do not predict infant outcomes well. This is in accordance with meta-analytic data, showing that sensitivity as originally defined by Ainsworth et al. (1978) accounts for a low percentage of the variance in attachment-approximately $6 \%$ and only approximately $2 \%$ among families with low socioeconomic status (Wolff and Van IJzendoorn, 1997). Relevant to our interest in physical contact and OT, Woodhouse et al. (2020) recently demonstrated which of the many maternal behaviors measured via the sensitivity construct have the strongest impact on infant attachment outcomes. They found that among low SES mothers, it was their capacity to engage in ventral-ventral contact in order to soothe their distressed infants to a fully calm and regulated state at least $50 \%$ of the time as well as allow relatively uninterrupted exploration, which mattered the most. Mastering these specific maternal behaviors increased their infants' chances of developing a secure attachment from about 30 to $71 \%$. These findings mirror those of the early attachment pioneers, which also noted strong links between maternal incompetence or rejection of providing physical contact and infant attachment quality (Ainsworth et al., 1978; Main and Stadtman, 1981).

One of the central findings of the rodent maternal developmental programming was the non-genomic transmission of maternal caregiving behaviors (Champagne and Meaney, 2001). Currently, no longitudinal cross-generational human data exist for the maternal capacity to engage in extended or even brief but sufficiently long bouts of ventral-ventral physical contact (cf. Woodhouse et al., 2020). However, during the home observations that was part of the pioneering work of Ainsworth et al. (1978) conducted to develop the Strange Situation for the assessment of infant attachment quality, some mothers were found to display aversion to physical contact stably across the first year of their childrens' lives, with resultant infant aggression, conflict behavior, and ultimately insecure-avoidant attachment (Main and Stadtman, 1981). Presumably, such mothers would be the human equivalent of the low LG-ABN rodent dams (Champagne and Meaney, 2001). Employing the Adult Attachment Interview, Main (1990) found links between maternal unresolved representations of received rejections to their childhood bids for physical contact toward their mother and contemporaneous observations of the interviewed mothers' aversion to physical contact with their infants. Hence, we have some retrospective longitudinal human evidence for the "like mother like daughter" mechanism found in rodents (Champagne and Meaney, 2001).

\section{Does the Support of Universal EPIC Among Caregivers of Healthy Full-Term Infants Constitute a Clinically Relevant and Scalable Intervention?}

For any intervention to be considered evidence-based in modern medicine, it would have to live up to the requirements of being (1) sufficiently empirically supported, (2) in accordance with the individual practitioner's clinical judgment, and (3) acceptable to the client. Whether an intervention is thought to be sufficiently empirically supported to warrant implementation presumably rests on several factors: the urgency of the medical challenge presented, efficacy and feasibility of alternative interventions, the relative financial and organizational demands of all potential interventions.

Do human suboptimum OT systems constitute a medical challenge that requires urgent action? First of all, how to meaningfully quantify proportions of the general population, affected by suboptimum OT systems? Links between OT, maternal attachment representations, maternal caregiving behavior, and infant attachment outcomes (Strathearn et al., 2009; Shah et al., 2010; Atzil et al., 2011; Galbally et al., 2011) suggest that population estimates of infant and adult insecure attachment might serve as a meaningful proxy. On this basis, approximately $40 \%$ of the general population will suffer from suboptimum OT systems/insecure attachment (van Ijzendoorn and Sagi-Schwartz, 2008; Bakermans-Kranenburg and van IJzendoorn, 2009; Moullin et al., 2014). Insecure attachment/suboptimum social functioning is increasingly recognized for its role in human physical and psychological disease (Puig et al., 2013; Holt-Lunstad, 2018; McDade and Harris, 2018; Ehrlich and Cassidy, 2019) as is the prophylaxis of the capacity to have positive social connections in the face of childhood trauma (Garner et al., 2012). This ought to make the prevention of children developing suboptimum OT systems an urgent challenge.

Meta-analysis of current infant attachment interventions, which tend to have a maternal representational (e.g., Juffer et al., 2017; Juffer and Bakermans-Kranenburg, 2018) and/or behavioral focus (Bakermans-Kranenburg et al., 2003; Dozier and Bernard, 2017; Caron et al., 2018; Hoye and Dozier, 2018), reveal relatively modest outcomes for infant attachment (Bakermans-Kranenburg et al., 2003; Wright and Edginton, 2016). Furthermore, the interventions mostly require relatively long and frequent individual therapeutic sessions, making them costly to implement (Wright and Edginton, 2016).

Judging from the studies conducted this far, supporting both low- and high-risk parents to successfully engage in EPIC appears feasible (Anisfeld et al., 1990; Bigelow and Power, 2012; Williams and Turner, 2020). However, postpartum specialized clinical support of EPIC may be necessary for greater compliance. To give an illustration of this: An Italian study provided 200 middleclass mothers either an infant carrier after the delivery (of which 65\% were cesarean) of their full-term healthy infants or a breastfeeding instruction pamphlet. Of the 100 mothers provided a carrier, 69 utilized it for at least $1 \mathrm{~h}$ /day during the first month of life, while 31 did not use it at all. Of the non-using mothers, 15 ascribed their non-use to cesarean pain. Other reasons for non-use was not feeling comfortable with the carrier or the infant crying while in the carrier (Pisacane et al., 2012). Theoretically, based on the findings of Main (1990) described above, some parents may have challenges in engaging in EPIC, based on their own childhood received rejections of their bids for physical contact. Parents' capacity to engage in 
EPIC may also be influenced by their own unresolved childhood trauma and autistic traits (Voos et al., 2013; Iyengar et al., 2014, 2019; Peled-Avron and Shamay-Tsoory, 2017). At this early stage of development of clinical implementation of EPIC, very little information exists as to the proportion of parents likely to face challenges engaging in close physical contact with their infant. Consequentially, therapeutic approaches to resolve such challenges have also yet to be defined and confirmed through testing. Potential therapeutic pathways could involve tactile components, such as massage, body psychotherapy, or psychomotor therapy, capitalizing on the OT research, which demonstrates links between received tactile stimulation, OT levels, and subsequent willingness and capacity to purposefully engage in conspecific social contact (Stock and Uvnäs-Moberg, 1988; Uvnäs-Moberg et al., 2005; Lukas et al., 2011). Massage and other manual touchrelated therapies, such as reflexology, have been shown to increase salivary and plasma OT levels in male (Morhenn et al., 2012; Li et al., 2018), female (Morhenn et al., 2012), puerperal (Yokoyama et al., 1994; Matthiesen et al., 2001), and autism spectrum disorder subjects (Tsuji et al., 2015), reduce stress and anxiety in a psychiatric inpatient ward (Garner et al., 2008), and, when delivered in several sessions antenatally, reduce labor pain and/or labor duration in parturient women (Nabb et al., 2006; Dolatian et al., 2011; McCullough et al., 2017), indicative of improved OT functioning (Uvnäs-Moberg et al., 2019). Other potential therapies, with a rich history of clinical application and presumably acting on and via OT mechanisms, could include parentinfant attachment-promoting body psychotherapy (Harms, 2015) or psychomotor interventions (Emck and Scheffers, 2019). However, all of these abovementioned therapies are yet to be rigorously and formally evaluated for the effectiveness in resolving parental discomfort or incapacity in relation to extended parent-infant contact, attesting to the scant research efforts invested toward implementation challenges of parent-full-term infant contacts practices in clinical settings, in stark contrast to the current state for parental-preterm infant contact (kangaroo mother care) (Bergh et al., 2016; Chan et al., 2017; Smith et al., 2017; Nimbalkar and Sadhwani, 2019).

\section{REFERENCES}

Abbott, K. (2016). Attachment During the First Year of Life: Validity and Longitudinal Associations to 14 Months, of Attachment classification at 7 months. Doctoral dissertation, University of Liverpool, Liverpool.

Agren, G., Lundeberg, T., Uvnäs-Moberg, K., and Sato, A. (1995). The oxytocin antagonist 1-deamino-2-D-Tyr-(Oet)-4-Thr-8-Orn-oxytocin reverses the increase in the withdrawal response latency to thermal, but not mechanical nociceptive stimuli following oxytocin administration or massagelike stroking in rats. Neurosci. Lett. 187, 49-52. doi: 10.1016/0304-3940(95) 11335-t

Ainsworth, M. D. S., Blehar, M. C., Waters, E., and Wall, S. (1978). Patterns of Attachment: A Psychological Study of the Strange Situation. Hoboken, NJ: Lawrence Erlbaum.

Alberts, J. R., and May, B. (1984). Nonnutritive, thermotactile induction of filial huddling in rat pups. Dev. Psychobiol. 17, 161-181. doi: 10.1002/dev.420170207

\section{CONCLUSION}

Impressive progress has been made in the past decades in understanding the OT-related biology of somatosensory stimulation and its links to animal and human social interaction, especially parent-offspring behavior (Champagne et al., 2001; Uvnäs-Moberg, 2015; Insel, 2016; Feldman and BakermansKranenburg, 2017). Much of the research in potential clinical applications of these biological discoveries have been invested in pharmacological approaches, targeting various social deficits, albeit with limited success (Bakermans-Kranenburg et al., 2013; Grimm et al., 2014; Hofmann et al., 2016; Quintana and Woolley, 2016). In recent years, a shift from the focus on primarily negative aspects of maternal mental health, such as symptoms of depression, anxiety, or states of distress and child maladaptation to positive maternal health and child resilienceinducing processes signals a growing awareness of the vital necessity to move at least some of the available research resources toward more preventative approaches (Feldman, 2020; Phua et al., 2020). Similarly, the emerging evidence for links between the capacity to engage in trustful relations-being securely attached-and physical health (Puig et al., 2013; HoltLunstad, 2018; McDade and Harris, 2018; Ehrlich and Cassidy, 2019) as well as the large proportion of the general population showing deficits in that very capacity (van Ijzendoorn and SagiSchwartz, 2008; Bakermans-Kranenburg and van IJzendoorn, 2009; Moullin et al., 2014) gives even greater urgency to confirm and implement scalable interventions. Supporting parents to engage in extended physical contact with their full-term healthy infants appears to bring about many of the animal OT- and sensory-stimulation-related effects and furthermore may be a comparatively low-cost and thus scalable intervention (Williams and Turner, 2020). With these perspectives, a clinical application of the hard-won insights over the past decades into fundamental affiliative and resilience-inducing biological mechanisms may be within reach.

\section{AUTHOR CONTRIBUTIONS}

HN wrote the manuscript.

Altemus, M., Fong, J., Yang, R., Damast, S., Luine, V., and Ferguson, D. (2004). Changes in cerebrospinal fluid neurochemistry during pregnancy. Biol. Psychiatry 56, 386-392. doi: 10.1016/j.biopsych.2004.06.002

Amico, J. A., and Hempel, J. (1990). An oxytocin precursor intermediate circulates in the plasma of humans and rhesus monkeys administered estrogen. Neuroendocrinology 51, 437-443. doi: 10.1159/000125371

Anisfeld, E., Casper, V., Nozyce, M., and Cunningham, N. (1990). Does infant carrying promote attachment? An experimental study of the effects of increased physical contact on the development of attachment. Child Dev. 61, 1617-1627. doi: $10.2307 / 1130769$

Aoki, Y., Yahata, N., Watanabe, T., Takano, Y., Kawakubo, Y., Kuwabara, H., et al. (2014). Oxytocin improves behavioural and neural deficits in inferring others' social emotions in autism. Brain J. Neurol. 137(Pt. 11), 3073-3086. doi: 10.1093/brain/awu231

Araki, T., Ito, K., Kurosawa, M., and Sato, A. (1984). Responses of adrenal sympathetic nerve activity and catecholamine secretion to cutaneous 
stimulation in anesthetized rats. Neuroscience 12, 289-299. doi: 10.1016/03064522(84)90154-4

Atzil, S., Hendler, T., and Feldman, R. (2011). Specifying the neurobiological basis of human attachment: brain, hormones, and behavior in synchronous and intrusive mothers. Neuropsychopharmacology 36, 2603-2615. doi: 10.1038/npp. 2011.172

Bakermans-Kranenburg, M. J., van, I., and Jzendoorn, M. H. (2013). Sniffing around oxytocin: review and meta-analyses of trials in healthy and clinical groups with implications for pharmacotherapy. Transl. Psychiatry 3:e258. doi: 10.1038/tp.2013.34

Bakermans-Kranenburg, M. J., and van IJzendoorn, M. H. (2009). The first 10,000 adult attachment interviews: distributions of adult attachment representations in clinical and non-clinical groups. Attach. Hum. Dev. 11, 223-263. doi: 10. 1080/14616730902814762

Bakermans-Kranenburg, M. J., van IJzendoorn, M. H., and Juffer, F. (2003). Less is more: meta-analyses of sensitivity and attachment interventions in early childhood. Psychol. Bull. 129, 195-215. doi: 10.1037/0033-2909.129.2.195

Bakermans-Kranenburg, M. J., van Ijzendoorn, M. H., Riem, M. M. E., Tops, M., and Alink, L. R. A. (2012). Oxytocin decreases handgrip force in reaction to infant crying in females without harsh parenting experiences. Soc. Cogn. Affect. Neurosci. 7, 951-957. doi: 10.1093/scan/nsr067

Barr, R. G., McMullan, S. J., Spiess, H., Leduc, D. G., Yaremko, J., Barfield, R., et al. (1991). Carrying as colic "therapy": a randomized controlled trial. Pediatrics 87, 623-630.

Bartz, J. A., Zaki, J., Bolger, N., Hollander, E., Ludwig, N. N., Kolevzon, A., et al. (2010). Oxytocin selectively improves empathic accuracy. Psychol. Sci. 21, 1426-1428. doi: 10.1177/0956797610383439

Bartz, J. A., Zaki, J., Bolger, N., and Ochsner, K. N. (2011). Social effects of oxytocin in humans: context and person matter. Trends Cogn. Sci. 15, 801-819. doi: 10.1016/j.tics.2011.05.002

Bergh, A.-M., de Graft-Johnson, J., Khadka, N., Om'Iniabohs, A., Udani, R., Pratomo, H., et al. (2016). The three waves in implementation of facility-based kangaroo mother care: a multi-country case study from Asia. BMC Int. Health Hum. Rights 16:4. doi: 10.1186/s12914-016-0080-4

Bigelow, A. E., and Gillis, D. E. (2010). Enhancing Baby's First Relationship: Results from a Study on Mother-Infant Skin-to-Skin Contact. Available online at: https://people.stfx.ca/abigelow/dvds-mother-infant-skin-to-skin-contact.htm (accessed December 7, 2019).

Bigelow, A. E., and Power, M. (2012). The effect of mother-infant skin-to-skin contact on infants' response to the still face task from newborn to three months of age. Infant Behav. Dev. 35, 240-251. doi: 10.1016/j.infbeh.2011.12.008

Bigelow, A. E., Power, M., Gillis, D. E., Maclellan-Peters, J., Alex, M., and McDonald, C. (2014). Breastfeeding, skin-to-skin contact, and mother-infant interactions over infants' first three months. Infant Mental Health J. 35, 51-62. doi: 10.1002/imhj.21424

Bigelow, A. E., Power, M., MacLean, K., Gillis, D. E., Ward, M., Taylor, C., et al. (2018). Mother-infant skin-to-skin contact and mother-child interaction 9 years later. Soc. Dev. 27, 937-951. doi: 10.1111/sode.12307

Bosch, O. J. (2013). Maternal aggression in rodents: brain oxytocin and vasopressin mediate pup defence. Philos. Trans. Royal Soc. B Biol. Sci. 368, 20130085. doi: 10.1098/rstb.2013.0085

Bosch, O. J., Meddle, S. L., Beiderbeck, D. I., Douglas, A. J., and Neumann, I. D. (2005). Brain oxytocin correlates with maternal aggression: link to anxiety. J. Neurosci. 25, 6807-6815. doi: 10.1523/JNEUROSCI.1342-05.2005

Bosch, O. J., and Neumann, I. D. (2012). Both oxytocin and vasopressin are mediators of maternal care and aggression in rodents: From central release to sites of action. Horm. Behav. 61, 293-303. doi: 10.1016/j.yhbeh.2011.11.002

Buchheim, A., Heinrichs, M., George, C., Pokorny, D., Koops, E., Henningsen, P., et al. (2009). Oxytocin enhances the experience of attachment security. Psychoneuroendocrinology 34, 1417-1422. doi: 10.1016/j.psyneuen.2009.04.002

Buemann, B., and Uvnäs-Moberg, K. (2020). Oxytocin may have a therapeutical potential against cardiovascular disease. Possible pharmaceutical and behavioral approaches. Med. Hypotheses 138:109597. doi: 10.1016/j.mehy.2020.109597

Buschdorf, J. P., and Meaney, M. J. (2015). Epigenetics/Programming in the HPA Axis. Compr. Physiol. 6, 87-110. doi: 10.1002/cphy.c140027

Bystrova, K., Ivanova, V., Edhborg, M., Matthiesen, A.-S., Ransjö-Arvidson, A.-B., Mukhamedrakhimov, R., et al. (2009). Early contact versus separation: Effects on mother-infant interaction one year later. Birth 36, 97-109. doi: 10.1111/j. 1523-536X.2009.00307.x

Bystrova, K., Matthiesen, A.-S., Vorontsov, I., Widström, A.-M., Ransjö-Arvidson, A.-B., and Uvnäs-Moberg, K. (2007). Maternal axillar and breast temperature after giving birth: Effects of delivery ward practices and relation to infant temperature. Birth 34, 291-300. doi: 10.1111/j.1523-536X.2007.00187.x

Bystrova, K., Widström, A. M., Matthiesen, A. S., Ransjö-Arvidson, A. B., WellesNyström, B., Wassberg, C., et al. (2003). Skin-to-skin contact may reduce negative consequences of "the stress of being born": A study on temperature in newborn infants, subjected to different ward routines in St. Petersburg. Acta Paediatr. 92, 320-326. doi: 10.1080/08035250310009248

Caldji, C., Diorio, J., and Meaney, M. J. (2000). Variations in maternal care in infancy regulate the development of stress reactivity. Biol. Psychiatry 48, 1164-1174. doi: 10.1016/s0006-3223(00)01084-2

Caron, E. B., Bernard, K., and Dozier, M. (2018). In vivo feedback predicts parent behavior change in the attachment and biobehavioral catch-up Intervention. J. Clin. Child Adoles. Psychol. 47, S35-S46. doi: 10.1080/15374416. 2016.1141359

Carson, D. S., Berquist, S. W., Trujillo, T. H., Garner, J. P., Hannah, S. L., Hyde, S. A., et al. (2015). Cerebrospinal fluid and plasma oxytocin concentrations are positively correlated and negatively predict anxiety in children. Mol. Psychiatry 20, 1085-1090. doi: 10.1038/mp.2014.132

Carter, C. S. (2014). Oxytocin pathways and the evolution of human behavior. Annu. Rev. Psychol. 65, 17-39. doi: 10.1146/annurev-psych-010213-115110

Carter, C. S. (2017). The oxytocin-vasopressin pathway in the context of love and fear. Front. Endocrinol. 8:356. doi: 10.3389/fendo.2017.00356

Carter, C. S., Boone, E. M., Pournajafi-Nazarloo, H., and Bales, K. L. (2009). Consequences of early experiences and exposure to oxytocin and vasopressin are sexually dimorphic. Dev. Neurosci. 31, 332-341. doi: 10.1159/000216544

Champagne, F. A. (2008). Epigenetic mechanisms and the transgenerational effects of maternal care. Front. Neuroendocrinol. 29:386-397. doi: 10.1016/j.yfrne.2008. 03.003

Champagne, F. A., Diorio, J., Sharma, S., and Meaney, M. J. (2001). Naturally occurring variations in maternal behavior in the rat are associated with differences in estrogen-inducible central oxytocin receptors. Proc. Natl. Acad. Sci. U.S.A. 98, 12736-12741. doi: 10.1073/pnas.221224598

Champagne, F. A., and Meaney, M. J. (2001). Like mother, like daughter: Evidence for non-genomic transmission of parental behavior and stress responsivity. Prog. Brain Res. 133, 287-302. doi: 10.1016/s0079-6123(01)33022-4

Champagne, F. A., Weaver, I. C. G., Diorio, J., Dymov, S., Szyf, M., and Meaney, M. J. (2006). Maternal care associated with methylation of the estrogen receptor-alphalb promoter and estrogen receptor-alpha expression in the medial preoptic area of female offspring. Endocrinology 147, 2909-2915. doi: 10.1210/en.2005-1119

Chan, G., Bergelson, I., Smith, E. R., Skotnes, T., and Wall, S. (2017). Barriers and enablers of kangaroo mother care implementation from a health systems perspective: A systematic review. Health Pol. Plan. 32, 1466-1475. doi: 10.1093/ heapol/czx098

Clodi, M., Vila, G., Geyeregger, R., Riedl, M., Stulnig, T. M., Struck, J., et al. (2008). Oxytocin alleviates the neuroendocrine and cytokine response to bacterial endotoxin in healthy men. Am. J. Physiol. Endocrinol. Metab. 295, E686-E691. doi: 10.1152/ajpendo.90263.2008

Colonnello, V., Petrocchi, N., Farinelli, M., and Ottaviani, C. (2017). Positive Social Interactions in a Lifespan Perspective with a Focus on opioidergic and oxytocinergic systems: implications for Neuroprotection. Curr. Neuropharmacol. 15, 543-561. doi: 10.2174/1570159X14666160816120209

Cong, X., Ludington-Hoe, S. M., Hussain, N., Cusson, R. M., Walsh, S., Vazquez, V., et al. (2015). Parental oxytocin responses during skin-to-skin contact in preterm infants. Early. Hum. Dev. 91, 401-406. doi: 10.1016/j.earlhumdev.2015.04. 012

Crnic, K. A., Ragozin, A. S., Greenberg, M. T., Robinson, N. M., and Basham, R. B. (1983). Social interaction and developmental Competence of Preterm and full-term infants during the first year of life. Child Dev. 54, 1199-1210. doi: $10.2307 / 1129675$

Dale, H. H. (1906). On some physiological actions of ergot. J. Physiol. 34, 163-206. doi: 10.1113/jphysiol.1906.sp001148

Dale, H. H. (1909). The action of extracts of the pituitary body. Biochem. J. 4, 427-447. doi: 10.1042/bj0040427 
De Cagna, F., Fusar-Poli, L., Damiani, S., Rocchetti, M., Giovanna, G., Mori, A., et al. (2019). The role of intranasal oxytocin in anxiety and depressive disorders: a systematic review of randomized controlled trials. Clin. Psychopharmacol. Neurosci. 17, 1-11. doi: 10.9758/cpn.2019.17.1.1

De Dreu, C. K. W., Greer, L. L., Handgraaf, M. J. J., Shalvi, S., Van Kleef, G. A., Baas, M., et al. (2010). The neuropeptide oxytocin regulates parochial altruism in intergroup conflict among humans. Science 328, 1408-1411. doi: 10.1126/ science. 1189047

Díaz-Cabiale, Z., Olausson, H., Sohlström, A., Agnati, L. F., Narváez, J. A., UvnäsMoberg, K., et al. (2004). Long-term modulation by postnatal oxytocin of the alpha 2 -adrenoceptor agonist binding sites in central autonomic regions and the role of prenatal stress. J. Neuroendocrinol. 16, 183-190. doi: 10.1111/j.09538194.2004.01146.x

Ding, C., Leow, M. K.-S., and Magkos, F. (2019). Oxytocin in metabolic homeostasis: implications for obesity and diabetes management. Obes. Rev. 20, 22-40. doi: 10.1111/obr.12757

Dolatian, M., Hasanpour, A., Montazeri, S., Heshmat, R., and Alavi Majd, H. (2011). The effect of reflexology on pain intensity and duration of labor on primiparas. Iranian Red. Crescent Med. J. 13, 475-479.

Dozier, M., and Bernard, K. (2017). Attachment and biobehavioral catch-up: addressing the needs of infants and toddlers exposed to inadequate or problematic caregiving. Curr. Opin. Psychol. 15, 111-117. doi: 10.1016/j.copsyc. 2017.03.003

Ehrlich, K. B., and Cassidy, J. (2019). Attachment and physical health: Introduction to the special issue. Attach. Hum. Dev. 21, 1-4. doi: 10.1080/14616734.2018. 1541512

Emck, C., and Scheffers, M. (2019). "Psychomotor interventions for mental health: An introduction," in Psychomotor interventions for mental health-Adults A movement- and body-oriented approach, eds J. de Lange, O. Glas, J. van Busschbach, C. Emck, and T. Scheewe (Amsterdam: Boom). doi: 10.4324/ 9781315623825-1

Eriksson, M., Lindh, B., Uvna"s-Moberg, K., and Ho"kfelt, T. (1996). Distribution and origin of peptide-containing nerve fibres in the rat and human mammary gland. Neuroscience 70, 227-245. doi: 10.1016/0306-4522(95) 00291-P

Esposito, G., Yoshida, S., Ohnishi, R., Tsuneoka, Y., Rostagno, M. D. C., Yokota, S., et al. (2013). Infant calming responses during maternal carrying in humans and mice. Curr. Biol. 23, 739-745. doi: 10.1016/j.cub.2013.03.041

Feldman, R. (2016). The neurobiology of mammalian parenting and the biosocial context of human caregiving. Horm. Behav. 77, 3-17. doi: 10.1016/j.yhbeh.2015. 10.001

Feldman, R. (2020). What is resilience: An affiliative neuroscience approach. World Psychiatry 19, 132-150. doi: 10.1002/wps.20729

Feldman, R., and Bakermans-Kranenburg, M. J. (2017). Oxytocin: a parenting hormone. Curr. Opin. Psychol. 15, 13-18. doi: 10.1016/j.copsyc.2017.02.011

Feldman, R., Rosenthal, Z., and Eidelman, A. I. (2014). Maternal-preterm skinto-skin contact enhances child physiologic organization and cognitive control across the first 10 years of life. Biol. Psychiatry 75, 56-64. doi: 10.1016/j. biopsych.2013.08.012

Feldman, R., Weller, A., Sirota, L., and Eidelman, A. I. (2002). Skin-to-Skin contact (Kangaroo care) promotes self-regulation in premature infants: Sleepwake cyclicity, arousal modulation, and sustained exploration. Dev. Psychol. 38, 194-207. doi: 10.1037/0012-1649.38.2.194

Francis, D. D., Champagne, F. C., and Meaney, M. J. (2000). Variations in maternal behaviour are associated with differences in oxytocin receptor levels in the rat. J. Neuroendocrinol. 12, 1145-1148. doi: 10.1046/j.1365-2826.2000.00599.x

Francis, D. D., Diorio, J., Liu, D., and Meaney, M. J. (1999). Nongenomic transmission across generations of maternal behavior and stress responses in the rat. Science 286, 1155-1158. doi: 10.1126/science.286.5442.1155

Francis, D. D., Young, L. J., Meaney, M. J., and Insel, T. R. (2002). Naturally occurring differences in maternal care are associated with the expression of oxytocin and vasopressin (V1a) receptors: Gender differences. J. Neuroendocrinol. 14, 349-353. doi: 10.1046/j.0007-1331.2002.00776.x

Fransson, A.-L., Karlsson, H., and Nilsson, K. (2005). Temperature variation in newborn babies: importance of physical contact with the mother. Arch. Dis. Childhood 90, F500-F504. doi: 10.1136/adc.2004.066589

Frijling, J. L. (2017). Preventing PTSD with oxytocin: Effects of oxytocin administration on fear neurocircuitry and PTSD symptom development in recently trauma-exposed individuals. Eur. J. Psychotraumatol. 8:1302652. doi: 10.1080/20008198.2017.1302652

Galbally, M., Lewis, A. J., Van Ijzendoorn, M. H., and Permezel, M. (2011). The role of oxytocin in mother-infant relations: a systematic review of human studies. Harv. Rev. Psychiatry 19, 1-14. doi: 10.3109/10673229.2011.549771

Garner, A. S., Shonkoff, J. P., and Committee on Psychosocial Aspects of Child and Family Health, Committee on Early Childhood, Adoption, and Dependent Care. (2012). Early childhood adversity, toxic stress, and the role of the pediatrician: translating developmental science into lifelong health. Pediatrics 129, e224-e231. doi: 10.1542/peds.2011-2662

Garner, B., Phillips, L. J., Schmidt, H.-M., Markulev, C., O’Connor, J., Wood, S. J., et al. (2008). Pilot study evaluating the effect of massage therapy on stress, anxiety and aggression in a young adult psychiatric inpatient unit. Aust. N.Z. J. Psychiatry 42, 414-422. doi: 10.1080/00048670801961131

Geng, Y., Zhao, W., Zhou, F., Ma, X., Yao, S., Hurlemann, R., et al. (2018). Oxytocin enhancement of emotional empathy: generalization across cultures and effects on amygdala activity. Front. Neurosci. 12:512. doi: 10.3389/fnins.2018.00512

Gimpl, G., and Fahrenholz, F. (2001). The oxytocin receptor system: Structure, function, and regulation. Physiol. Rev. 81, 629-683. doi: 10.1152/physrev.2001. 81.2.629

Gonzalez, A., Lovic, V., Ward, G. R., Wainwright, P. E., and Fleming, A. S. (2001). Intergenerational effects of complete maternal deprivation and replacement stimulation on maternal behavior and emotionality in female rats. Dev. Psychobiol. 38, 11-32. doi: 10.1002/1098-2302(2001)38:1<11::aid-dev2>3.0.co; 2-b

Graham, S. M., Manara, J., Chokotho, L., and Harrison, W. J. (2015). Back-carrying infants to prevent developmental hip dysplasia and its sequelae: Is a new public health initiative needed? J. Pediatric Orthop. 35, 57-61. doi: 10.1097/BPO. 0000000000000234

Green, L., Fein, D., Modahl, C., Feinstein, C., Waterhouse, L., and Morris, M. (2001). Oxytocin and autistic disorder: alterations in peptide forms. Biol. Psychiatry 50, 609-613. doi: 10.1016/s0006-3223(01)01139-8

Grimm, S., Pestke, K., Feeser, M., Aust, S., Weigand, A., Wang, J., et al. (2014). Early life stress modulates oxytocin effects on limbic system during acute psychosocial stress. Soc. Cogn. Affect. Neurosci. 9, 1828-1835. doi: 10.1093/scan/nsu020

Guastella, A. J., Einfeld, S. L., Gray, K. M., Rinehart, N. J., Tonge, B. J., Lambert, T. J., et al. (2010). Intranasal oxytocin improves emotion recognition for youth with autism spectrum disorders. Biol. Psychiatry 67, 692-694. doi: 10.1016/j. biopsych.2009.09.020

Hammock, E. A. D. (2015). Developmental perspectives on oxytocin and vasopressin. Neuropsychopharmacology 40, 24-42. doi: 10.1038/npp.2014.120

Harms, T. (2015). "Body Psychotherapy with Parents, Babies, and Infants," in The Handbook of Body Psychotherapy and Somatic Psychology, eds G. Marlock, H. Weiss, C. Young, and M. Soth (Berkeley, CA: North Atlantic Books), $776-786$.

Hatton, G. I., Perlmutter, L. S., Salm, A. K., and Tweedle, C. D. (1984). Dynamic neuronal-glial interactions in hypothalamus and pituitary: Implications for control of hormone synthesis and release. Peptides 5(Suppl. 1), 121-138. doi: 10.1016/0196-9781(84)90271-7

Heinrichs, M., Baumgartner, T., Kirschbaum, C., and Ehlert, U. (2003). Social support and oxytocin interact to suppress cortisol and subjective responses to psychosocial stress. Biol. Psychiatry 54, 1389-1398. doi: 10.1016/s0006-3223(03) 00465-7

Higashida, H., Munesue, T., Kosaka, H., Yamasue, H., Yokoyama, S., and Kikuchi, M. (2019). Social interaction improved by oxytocin in the subclass of autism with comorbid intellectual disabilities. Diseases 7:24. doi: 10.3390/ diseases7010024

Hofmann, S. G., Fang, A., and Brager, D. N. (2016). Notice of retraction and replacement: hofmann et al. effect of intranasal oxytocin administration on psychiatric symptoms: a meta-analysis of placebo-controlled studies. Psychiatry Res. 228, 708-714. doi: 10.1016/j.psychres.2015.05.039

Hollander, E., Bartz, J., Chaplin, W., Phillips, A., Sumner, J., Soorya, L., et al. (2007). Oxytocin increases retention of social cognition in autism. Biol. Psychiatry 61, 498-503. doi: 10.1016/j.biopsych.2006.05.030

Hollander, E., Novotny, S., Hanratty, M., Yaffe, R., DeCaria, C. M., Aronowitz, B. R., et al. (2003). Oxytocin infusion reduces repetitive behaviors in adults with autistic and Asperger's disorders. Neuropsychopharmacology 28, 193-198. doi: $10.1038 /$ sj.npp. 1300021 
Holst, S., Lund, I., Petersson, M., and Uvnäs-Moberg, K. (2005). Massagelike stroking influences plasma levels of gastrointestinal hormones, including insulin, and increases weight gain in male rats. Auton. Neurosci. Basic Clin. 120, 73-79. doi: 10.1016/j.autneu.2005.04.007

Holst, S., Uvnäs-Moberg, K., and Petersson, M. (2002). Postnatal oxytocin treatment and postnatal stroking of rats reduce blood pressure in adulthood. Auton. Neurosci. Basic Clin. 99, 85-90. doi: 10.1016/s1566-0702(02) 00134-0

Holt-Lunstad, J. (2018). Why social relationships are important for physical health: a systems approach to understanding and modifying risk and protection. Annu. Rev. Psychol. 69, 437-458. doi: 10.1146/annurev-psych-122216-011902

Horta, M., Kaylor, K., Feifel, D., and Ebner, N. C. (2020). Chronic oxytocin administration as a tool for investigation and treatment: a cross-disciplinary systematic review. Neurosci. Biobehav. Rev. 108, 1-23. doi: 10.1016/j.neubiorev. 2019.10.012

Horvat-Gordon, M., Granger, D. A., Schwartz, E. B., Nelson, V. J., and Kivlighan, K. T. (2005). Oxytocin is not a valid biomarker when measured in saliva by immunoassay. Physiol. Behav. 84, 445-448. doi: 10.1016/j.physbeh.2005.01.007

Hoye, J. R., and Dozier, M. (2018). Implementing attachment and Biobehavioral Catch-Up with birth parents: rationale and case example. J. Clin. Psychol. 74, 1300-1307. doi: 10.1002/jclp.22641

Hunziker, U. A., and Barr, R. G. (1986). Increased carrying reduces infant crying: a randomized controlled trial. Pediatrics 77, 641-648.

Hurlemann, R., Patin, A., Onur, O. A., Cohen, M. X., Baumgartner, T., Metzler, S., et al. (2010). Oxytocin enhances amygdala-dependent, socially reinforced learning and emotional empathy in humans. J. Neurosci. 30, 4999-5007. doi: 10.1523/JNEUROSCI.5538-09.2010

Insel, T. R. (2010). The challenge of translation in social neuroscience: a review of oxytocin, vasopressin, and affiliative behavior. Neuron 65, 768-779. doi: 10.1016/j.neuron.2010.03.005

Insel, T. R. (2016). Translating Oxytocin Neuroscience to the Clinic: A National Institute of Mental Health Perspective. Biol. Psychiatry 79, 153-154. doi: 10. 1016/j.biopsych.2015.02.002

Institute for Health \& Work. (2015). Primary, Secondary and Tertiary Prevention. Available online at: https://www.iwh.on.ca/what-researchers-meanby/primary-secondary-and-tertiary-prevention (accessed January 21, 2020).

Iyengar, U., Kim, S., Martinez, S., Fonagy, P., and Strathearn, L. (2014). Unresolved trauma in mothers: intergenerational effects and the role of reorganization. Front. Psychol. 5:966. doi: 10.3389/fpsyg.2014.00966

Iyengar, U., Rajhans, P., Fonagy, P., Strathearn, L., and Kim, S. (2019). Unresolved trauma and reorganization in mothers: attachment and neuroscience perspectives. Front. Psychol. 10:110. doi: 10.3389/fpsyg.2019.00110

Jarskog, L., Pedersen, C. A., Johnson, J., Hamer, R., Rau, S., Elliott, T., et al. (2017). A 12-week randomized controlled trial of twice-daily intranasal oxytocin for social cognitive deficits in people with schizophrenia. Schizophr. Res. 185, 88-95. doi: 10.1016/j.schres.2017.01.008

Jonas, W., Nissen, E., Ransjö-Arvidson, A. B., Matthiesen, A. S., and UvnäsMoberg, K. (2008). Influence of oxytocin or epidural analgesia on personality profile in breastfeeding women: a comparative study. Arch. Women's Mental Health 11, 335-345. doi: 10.1007/s00737-008-0027-4

Jones, C., Barrera, I., Brothers, S., Ring, R., and Wahlestedt, C. (2017). Oxytocin and social functioning. Dialogues Clin. Neurosci. 19:10.

Juffer, F., and Bakermans-Kranenburg, M. J. (2018). Working with video-feedback intervention to promote positive parenting and sensitive discipline (VIPP-SD): a case study. J. Clin. Psychol. 74, 1346-1357. doi: 10.1002/jclp.22645

Juffer, F., Bakermans-Kranenburg, M. J., and van IJzendoorn, M. H. (2017). Pairing attachment theory and social learning theory in video-feedback intervention to promote positive parenting. Curr. Opin. Psychol. 15, 189-194. doi: 10.1016/j. copsyc.2017.03.012

Kagerbauer, S. M., Martin, J., Schuster, T., Blobner, M., Kochs, E. F., and Landgraf, R. (2013). Plasma oxytocin and vasopressin do not predict neuropeptide concentrations in human cerebrospinal fluid. J. Neuroendocrinol. 25, 668-673. doi: $10.1111 /$ jne. 12038

Kim, S. (2015). The mind in the making: developmental and neurobiological origins of mentalizing. Personal. Disord. 6, 356-365. doi: 10.1037/per0000102

Kim, S., Soeken, T. A., Cromer, S. J., Martinez, S. R., Hardy, L. R., and Strathearn, L. (2014). Oxytocin and postpartum depression: Delivering on what's known and what's not. Brain Res. 1580, 219-232. doi: 10.1016/j.brainres.2013.11.009
Kim, S., and Strathearn, L. (2016). Oxytocin and maternal brain plasticity. New Dir. Child Adolesc. Dev. 2016, 59-72. doi: 10.1002/cad.20170

Kirsch, P., Esslinger, C., Chen, Q., Mier, D., Lis, S., Siddhanti, S., et al. (2005). Oxytocin modulates neural circuitry for social cognition and fear in humans. J. Neurosci. 25, 11489-11493. doi: 10.1523/JNEUROSCI.3984-05.2005

Klopfer, P. H. (1971). Mother love: what turns it on? Am. Scient. 59, 404-407.

Klopfer, P. H., and Klopfer, M. S. (1968). Maternal "Imprinting" in Goats: Fostering of alien young. Zeitschrift Für Tierpsychologie 25, 862-866. doi: 10.1111/j.14390310.1968.tb00048.x

Kojima, S., and Alberts, J. R. (2009). Maternal care can rapidly induce an odorguided huddling preference in rat pups. Dev. Psychobiol. 51, 95-105. doi: 10. 1002/dev.20349

Kojima, S., and Alberts, J. R. (2011). Warmth from skin-to-skin contact with mother is essential for the acquisition of filial huddling preference in preweanling rats. Dev. Psychobiol. 53, 813-827. doi: 10.1002/dev.20565

Kojima, S., Stewart, R. A., Demas, G. E., and Alberts, J. R. (2012). Maternal contact differentially modulates central and peripheral oxytocin in rat pups during a brief regime of mother-pup interaction that induces a filial huddling preference. J. Neuroendocrinol. 24, 831-840. doi: 10.1111/j.1365-2826.2012.02280.x

Kosfeld, M., Heinrichs, M., Zak, P. J., Fischbacher, U., and Fehr, E. (2005). Oxytocin increases trust in humans. Nature 435, 673-676. doi: 10.1038/nature03701

Lawson, E. A., Olszewski, P. K., Weller, A., and Blevins, J. E. (2020). The role of oxytocin in regulation of appetitive behaviour, body weight and glucose homeostasis. J. Neuroendocrinol. 32, e12805. doi: 10.1111/jne.12805

Lee, M. H., and Williams, D. I. (1974). Changes in licking behaviour of rat mother following handling of young. Anim. Behav. 22, 679-681. doi: 10.1016/S00033472(74)80016-3

Leng, G., and Ludwig, M. (2016). Intranasal oxytocin: myths and delusions. Biol. Psychiatry 79, 243-250. doi: 10.1016/j.biopsych.2015.05.003

Levine, S., and Lewis, G. W. (1959). Critical period for effects of infantile experience on maturation of stress response. Science 129, 42-43. doi: 10.1126/science.129. 3340.42

Li, Q., Becker, B., Wernicke, J., Chen, Y., Zhang, Y., Li, R., et al. (2018). Foot massage evokes oxytocin release and activation of orbitofrontal cortex and superior temporal sulcus. Psychoneuroendocrinology 101, 193-203. doi: 10. 1016/j.psyneuen.2018.11.016

Liu, D., Diorio, J., Day, J. C., Francis, D. D., and Meaney, M. J. (2000). Maternal care, hippocampal synaptogenesis and cognitive development in rats. Nat. Neurosci. 3, 799-806. doi: 10.1038/77702

Liu, D., Diorio, J., Tannenbaum, B., Caldji, C., Francis, D. D., Freedman, A., et al. (1997). Maternal care, hippocampal glucocorticoid receptors, and hypothalamic-pituitary-adrenal responses to stress. Science 277, 1659-1662. doi: $10.1126 /$ science.277.5332.1659

Lovic, V., and Fleming, A. S. (2004). Artificially-reared female rats show reduced prepulse inhibition and deficits in the attentional set shifting task-Reversal of effects with maternal-like licking stimulation. Behav. Brain Res. 148, 209-219. doi: $10.1016 / \mathrm{s} 0166-4328(03) 00206-7$

Ludwig, M., and Leng, G. (2006). Dendritic peptide release and peptide-dependent behaviours. Nat. Rev. Neurosci. 7, 126-136. doi: 10.1038/nrn1845

Lukas, M., Toth, I., Reber, S. O., Slattery, D. A., Veenema, A. H., and Neumann, I. D. (2011). The neuropeptide oxytocin facilitates pro-social behavior and prevents social avoidance in rats and mice. Neuropsychopharmacology 36, 2159-2168. doi: 10.1038/npp.2011.95

Lund, I., Lundeberg, T., Kurosawa, M., and Uvnäs-Moberg, K. (1999). Sensory stimulation (massage) reduces blood pressure in unanaesthetized rats. J. Auton. Nervous Syst. 78, 30-37. doi: 10.1016/s0165-1838(99)00055-7

MacDonald, K., and MacDonald, T. M. (2010). The peptide that binds: a systematic review of oxytocin and its prosocial effects in humans. Harv. Rev. Psychiatry 18, 1-21. doi: 10.3109/10673220903523615

MacDonald, K., MacDonald, T. M., Brüne, M., Lamb, K., Wilson, M. P., Golshan, S., et al. (2013). Oxytocin and psychotherapy: a pilot study of its physiological, behavioral and subjective effects in males with depression. Psychoneuroendocrinology 38, 2831-2843. doi: 10.1016/j.psyneuen.2013.05.014

Macdonald, K. S. (2012). Sex, receptors, and attachment: a review of individual factors influencing response to oxytocin. Front. Neurosci. 6:194. doi: 10.3389/ fnins.2012.00194

MacLean, E. L., Wilson, S. R., Martin, W. L., Davis, J. M., Nazarloo, H. P., and Carter, C. S. (2019). Challenges for measuring oxytocin: the blind men and 
the elephant? Psychoneuroendocrinology 107, 225-231. doi: 10.1016/j.psyneuen. 2019.05.018

Mah, B. L. (2016). Oxytocin, postnatal depression, and parenting: a systematic review. Harv. Rev. Psychiatry 24, 1-13. doi: 10.1097/HRP.0000000000000093

Main, M. (1990). Parental aversion to infant-initiated contact is correlated with the parent's own rejection during childhood: The effects of experience on signals of security with respect to attachment. In Touch: The foundation of experience: Full revised and expanded proceedings of Johnson \& Johnson Pediatric Round Table $X$. Madison, CT: International Universities Press, Inc, 461-495.

Main, M., Kaplan, N., and Cassidy, J. (1985). Security in infancy, childhood, and adulthood: a move to the level of representation. Monogr. Soc. Res. Child Dev 50, 66-104. doi: 10.2307/3333827

Main, M., and Stadtman, J. (1981). Infant response to rejection of physical contact by the mother. J. Am. Acad. Child Psychiatry 20, 292-307. doi: 10.1016/S00027138(09)60990-0

Marsh, A. A., Yu, H. H., Pine, D. S., and Blair, R. J. R. (2010). Oxytocin improves specific recognition of positive facial expressions. Psychopharmacology 209, 225-232. doi: 10.1007/s00213-010-1780-4

Matthiesen, A. S., Ransjö-Arvidson, A. B., Nissen, E., and Uvnäs-Moberg, K. (2001). Postpartum maternal oxytocin release by newborns: Effects of infant hand massage and sucking. Birth 28, 13-19. doi: 10.1046/j.1523-536x.2001. 00013.x

McCullough, J. E. M., Close, C., Liddle, S. D., Sinclair, M., and Hughes, C. M. (2017). A pilot randomised controlled trial exploring the effects of antenatal reflexology on labour outcomes. Midwifery 55, 137-144. doi: 10.1016/j.midw. 2017.09.006

McCullough, M. E., Churchland, P. S., and Mendez, A. J. (2013). Problems with measuring peripheral oxytocin: can the data on oxytocin and human behavior be trusted? Neurosci. Biobehav. Rev. 37, 1485-1492. doi: 10.1016/j.neubiorev. 2013.04.018

McDade, T. W., and Harris, K. M. (2018). The biosocial approach to human development, behavior, and health across the life course. Russell Sage Found. J. Soc. Sci. 4, 2-26. doi: 10.7758/RSF.2018.4.4.01

McQuaid, R. J., McInnis, O. A., Abizaid, A., and Anisman, H. (2014). Making room for oxytocin in understanding depression. Neurosci. Biobehav. Rev. 45, 305-322. doi: 10.1016/j.neubiorev.2014.07.005

Meaney, M. J. (2001). Maternal care, gene expression, and the transmission of individual differences in stress reactivity across generations. Annu. Rev. Neurosci. 24, 1161-1192. doi: 10.1146/annurev.neuro.24.1.1161

Meaney, M. J., and Aitken, D. H. (1985). The effects of early postnatal handling on hippocampal glucocorticoid receptor concentrations: temporal parameters. Brain Res. 354, 301-314. doi: 10.1016/0165-3806(85)90183-x

Meaney, M. J., Diorio, J., Francis, D. D., Widdowson, J., LaPlante, P., Caldji, C., et al. (1996). Early environmental regulation of forebrain glucocorticoid receptor gene expression: Implications for adrenocortical responses to stress. Dev. Neurosci. 18, 49-72. doi: 10.1159/000111395

Mesman, J., van IJzendoorn, M. H., and Bakermans-Kranenburg, M. J. (2009). The many faces of the still-face paradigm: a review and meta-analysis. Dev.. Rev. 29, 120-162. doi: 10.1016/j.dr.2009.02.001

Meyer, P. M., and Alberts, J. R. (2016). Non-nutritive, thermotactile cues induce odor preference in infant mice (Mus musculus). J. Comp. Psychol. 130, 369-379. doi: $10.1037 /$ com 0000044

Meyer-Lindenberg, A., Domes, G., Kirsch, P., and Heinrichs, M. (2011). Oxytocin and vasopressin in the human brain: social neuropeptides for translational medicine. Nat. Rev. Neurosci. 12, 524-538. doi: 10.1038/nrn3044

Moberg, K. U., Handlin, L., and Petersson, M. (2020). Neuroendocrine mechanisms involved in the physiological effects caused by skin-to-skin contact-With a particular focus on the oxytocinergic system. Infant Behav. Dev. 61:101482. doi: 10.1016/j.infbeh.2020.101482

Morgan, B. E., Horn, A. R., and Bergman, N. J. (2011). Should neonates sleep alone? Biol. Psychiatry 70, 817-825. doi: 10.1016/j.biopsych.2011.06.018

Morhenn, V., Beavin, L. E., and Zak, P. J. (2012). Massage increases oxytocin and reduces adrenocorticotropin hormone in humans. Altern. Ther. Health Med. 18, $11-18$.

Moullin, S., Waldfogel, J., and Washbrook, E. (2014). Baby Bonds: Parenting, Attachment and A Secure Base for Children. London: The Sutton Trust.

Murgatroyd, C., Quinn, J. P., Sharp, H. M., Pickles, A., and Hill, J. (2015). Effects of prenatal and postnatal depression, and maternal stroking, at the glucocorticoid receptor gene. Transl. Psychiatry 5:e560. doi: 10.1038/tp.2014. 140

Murray, L., Fiori-Cowley, A., Hooper, R., and Cooper, P. (1996). The impact of postnatal depression and associated adversity on early mother-infant interactions and later infant outcome. Child Dev. 67, 2512-2526. doi: 10.2307/ 1131637

Myers, M. M., Brunelli, S. A., Shair, H. N., Squire, J. M., and Hofer, M. A. (1989a). Relationships between maternal behavior of SHR and WKY dams and adult blood pressures of cross-fostered F1 pups. Dev. Psychobiol. 22, 55-67. doi: 10.1002/dev.420220105

Myers, M. M., Brunelli, S. A., Squire, J. M., Shindeldecker, R. D., and Hofer, M. A. (1989b). Maternal behavior of SHR rats and its relationship to offspring blood pressures. Dev. Psychobiol. 22, 29-53. doi: 10.1002/dev.420220104

Nabb, M. T. M., Kimber, L., Haines, A., and McCourt, C. (2006). Does regular massage from late pregnancy to birth decrease maternal pain perception during labour and birth?-A feasibility study to investigate a programme of massage, controlled breathing and visualization, from 36 weeks of pregnancy until birth. Compl. Ther. Clin. Pract. 12, 222-231. doi: 10.1016/j.ctcp.2005.12.006

Ne'eman, R., Perach-Barzilay, N., Fischer-Shofty, M., Atias, A., and ShamayTsoory, S. G. (2016). Intranasal administration of oxytocin increases human aggressive behavior. Horm. Behav. 80, 125-131. doi: 10.1016/j.yhbeh.2016.01. 015

Nelson, E. E., Alberts, J. R., Tian, Y., and Verbalis, J. G. (1998). Oxytocin is elevated in plasma of 10-day-old rats following gastric distension. Dev. Brain Res. 111, 301-303. doi: 10.1016/S0165-3806(98)00147-3

Nimbalkar, S., and Sadhwani, N. (2019). Implementation of Kangaroo Mother Care-challenges and solutions. Indian Pediatr. 56, 725-729. doi: 10.1007/ s13312-019-1635-y

Norholt, H. (2020). Revisiting the roots of attachment: a review of the biological and psychological effects of maternal skin-to-skin contact and carrying of full-term infants. Infant Behav. Dev. 60:101441. doi: 10.1016/j.infbeh.2020. 101441

Ott, L., and Scott, J. (1910). The action of infundibulum upon mammary secretion. Proc. Soc. Exp. Biol. Med. 1910, 48-49. doi: 10.3181/00379727-8-27

Pedersen, C. A. (2004). Biological aspects of social bonding and the roots of human violence. Ann. N.Y. Acad. Sci. 1036, 106-127. doi: 10.1196/annals. 1330. 006

Pedersen, C. A. (2017). Oxytocin, tolerance, and the dark side of addiction. Int. Rev. Neurobiol. 136, 239-274. doi: 10.1016/bs.irn.2017.08.003

Pedersen, C. A., Ascher, J. A., Monroe, Y. L., and Prange, A. J. (1982). Oxytocin induces maternal behavior in virgin female rats. Science 216, 648-650. doi: 10.1126/science.7071605

Pedersen, C. A., and Boccia, M. L. (2002). Oxytocin links mothering received, mothering bestowed and adult stress responses. Stress 5, 259-267. doi: 10.1080/ 1025389021000037586

Pedersen, C. A., and Prange, A. J. (1979). Induction of maternal behavior in virgin rats after intracerebroventricular administration of oxytocin. Proc. Natl. Acad. Sci. U.S.A. 76, 6661-6665. doi: 10.1073/pnas.76.12.6661

Pedersen, C. A., Smedley, K. L., Leserman, J., Jarskog, L. F., Rau, S. W., KampovPolevoi, A., et al. (2013). Intranasal oxytocin blocks alcohol withdrawal in human subjects. Alcohol. Clin. Exp. Res. 37, 484-489. doi: 10.1111/j.1530-0277. 2012.01958.x

Peled-Avron, L., and Shamay-Tsoory, S. G. (2017). Don't touch me! Autistic traits modulate early and late ERP components during visual perception of social touch. Autism Res. 10, 1141-1154. doi: 10.1002/aur.1762

Peña, C. J., Neugut, Y. D., and Champagne, F. A. (2013). Developmental timing of the effects of maternal care on gene expression and epigenetic regulation of hormone receptor levels in female rats. Endocrinology 154, 4340-4351. doi: 10.1210/en.2013-1595

Perel, P., Roberts, I., Sena, E., Wheble, P., Briscoe, C., Sandercock, P., et al. (2007). Comparison of treatment effects between animal experiments and clinical trials: Systematic review. BMJ 334:197. doi: 10.1136/bmj.39048. 407928.BE

Phua, D. Y., Kee, M. Z. L., and Meaney, M. J. (2020). Positive maternal mental health, parenting, and child development. Biol. Psychiatry 87, 328-337. doi: 10.1016/j.biopsych.2019.09.028

Pickles, A., Sharp, H., Hellier, J., and Hill, J. (2017). Prenatal anxiety, maternal stroking in infancy, and symptoms of emotional and behavioral disorders at 
3.5 years. Eur. Child Adoles. Psychiatry 26, 325-334. doi: 10.1007/s00787-0160886-6

Pisacane, A., Continisio, P., Filosa, C., Tagliamonte, V., and Continisio, G. I. (2012). Use of baby carriers to increase breastfeeding duration among term infants: the effects of an educational intervention in Italy. Acta Paediatr. 101, e434-e438. doi: 10.1111/j.1651-2227.2012.02758.x

Porges, S. W., Davila, M. I., Lewis, G. F., Kolacz, J., Okonmah-Obazee, S., Hane, A. A., et al. (2019). Autonomic regulation of preterm infants is enhanced by Family Nurture Intervention. Dev. Psychobiol. 61, 942-952. doi: 10.1002/dev. 21841

Puig, J., Englund, M. M., Simpson, J. A., and Collins, W. A. (2013). Predicting adult physical illness from infant attachment: a prospective longitudinal study. Health Psychol. 32, 409-417. doi: 10.1037/a0028889

Quintana, D. S., Westlye, L. T., Smerud, K. T., Mahmoud, R. A., Andreassen, O. A., and Djupesland, P. G. (2018). Saliva oxytocin measures do not reflect peripheral plasma concentrations after intranasal oxytocin administration in men. Horm. Behav. 102, 85-92. doi: 10.1016/j.yhbeh.2018.05.004

Quintana, D. S., and Woolley, J. D. (2016). Intranasal oxytocin mechanisms can be better understood, but its effects on social cognition and behavior are not to be sniffed at. Biol. Psychiatry 79, e49-e50. doi: 10.1016/j.biopsych.2015. 06.021

Riem, M. M. E., van IJzendoorn, M. H., Tops, M., Boksem, M. A. S., Rombouts, S. A. R. B., and Bakermans-Kranenburg, M. J. (2013). Oxytocin effects on complex brain networks are moderated by experiences of maternal love withdrawal. Eur. Neuropsychopharmacol. 23, 1288-1295. doi: 10.1016/j. euroneuro.2013.01.011

Rilling, J. K., and Young, L. J. (2014). The biology of mammalian parenting and its effect on offspring social development. Science 345, 771-776. doi: 10.1126/ science. 1252723

Robinson, K. J., Bosch, O. J., Levkowitz, G., Busch, K. E., Jarman, A. P., and Ludwig, M. (2019). Social creatures: model animal systems for studying the neuroendocrine mechanisms of social behaviour. J. Neuroendocrinol. 31:e12807. doi: 10.1111/jne.12807

Sato, A., and Schmidt, R. F. (1987). The modulation of visceral functions by somatic afferent activity. Japanese J. Physiol. 37, 1-17. doi: 10.2170/jjphysiol.37.1

Scantamburlo, G., Hansenne, M., Geenen, V., Legros, J. J., and Ansseau, M. (2015). Additional intranasal oxytocin to escitalopram improves depressive symptoms in resistant depression: an open trial. Eur. Psychiatry 30, 65-68. doi: 10.1016/j. eurpsy.2014.08.007

Shah, P. E., Fonagy, P., and Strathearn, L. (2010). Is attachment transmitted across generations? The plot thickens. Clin. Child Psychol. Psychiatry 15, 329-345. doi: $10.1177 / 1359104510365449$

Shapiro, L. E., and Insel, T. R. (1989). Ontogeny of oxytocin receptors in rat forebrain: a quantitative study. Synapse 4, 259-266. doi: 10.1002/syn.890040312

Sharp, H., Hill, J., Hellier, J., and Pickles, A. (2015). Maternal antenatal anxiety, postnatal stroking and emotional problems in children: outcomes predicted from pre- and postnatal programming hypotheses. Psychol. Med. 45, 269-283. doi: 10.1017/S0033291714001342

Smith, E. R., Bergelson, I., Constantian, S., Valsangkar, B., and Chan, G. J. (2017). Barriers and enablers of health system adoption of kangaroo mother care: a systematic review of caregiver perspectives. BMC Pediatr. 17:35. doi: 10.1186/ s12887-016-0769-5

Sohlström, A., Carlsson, C., and Uvnäs-Moberg, K. (2000). Effects of oxytocin treatment in early life on body weight and corticosterone in adult offspring from ad libitum-fed and food-restricted rats. Biol. Neonate 78, 33-40. doi: $10.1159 / 000014244$

St James-Roberts, I. (2008). Infant crying and sleeping: helping parents to prevent and manage problems. Prim. Care 35, 547-567. doi: 10.1016/j.pop.2008.06.004

St James-Roberts, I., Alvarez, M., Csipke, E., Abramsky, T., Goodwin, J., and Sorgenfrei, E. (2006). Infant crying and sleeping in London, Copenhagen and when parents adopt a "proximal" form of care. Pediatrics 117, e1146-e1155. doi: 10.1542 /peds.2005-2387

St James-Roberts, I., Hurry, J., Bowyer, J., and Barr, R. G. (1995). Supplementary carrying compared with advice to increase responsive parenting as interventions to prevent persistent infant crying. Pediatrics 95, 381-388.

Stock, S., and Uvnäs-Moberg, K. (1988). Increased plasma levels of oxytocin in response to afferent electrical stimulation of the sciatic and vagal nerves and in response to touch and pinch in anaesthetized rats. Acta Physiol. Scand. 132, 29-34. doi: 10.1111/j.1748-1716.1988.tb08294.x

Strathearn, L. (2011). Maternal neglect: Oxytocin, dopamine and the neurobiology of attachment. J. Neuroendocrinol. 23, 1054-1065. doi: 10.1111/j.1365-2826. 2011.02228.x

Strathearn, L., Fonagy, P., Amico, J., and Montague, P. R. (2009). Adult attachment predicts maternal brain and oxytocin response to infant cues. Neuropsychopharmacology 34, 2655-2666. doi: 10.1038/npp. 2009.103

Strathearn, L., Mertens, C. E., Mayes, L., Rutherford, H., Rajhans, P., Xu, G., et al. (2019). Pathways relating the neurobiology of attachment to drug addiction. Front. Psychiatry 10:737. doi: 10.3389/fpsyt.2019.00737

Sue Carter, C., Pournajafi-Nazarloo, H., Kramer, K. M., Ziegler, T. E., White-Traut, R., Bello, D., et al. (2007). Oxytocin: behavioral associations and potential as a salivary biomarker. Ann. N.Y. Acad. Sci. 1098, 312-322. doi: 10.1196/annals. 1384.006

Szeto, A., McCabe, P. M., Nation, D. A., Tabak, B. A., Rossetti, M. A., McCullough, M. E., et al. (2011). Evaluation of enzyme immunoassay and radioimmunoassay methods for the measurement of plasma oxytocin. Psychosom. Med. 73, 393400. doi: 10.1097/PSY.0b013e31821df0c2

Tabak, B. A. (2013). Oxytocin and social salience: a call for geneenvironment interaction research. Front. Neurosci. 7:199. doi: 10.3389/ fnins.2013.00199

Tauber, M., Mantoulan, C., Copet, P., Jauregui, J., Demeer, G., Diene, G., et al. (2011). Oxytocin may be useful to increase trust in others and decrease disruptive behaviours in patients with Prader-Willi syndrome: a randomised placebo-controlled trial in 24 patients. Orphanet J. Rare Dis. 6:47. doi: 10.1186/ 1750-1172-6-47

Theodosis, D. T. (2002). Oxytocin-secreting neurons: A physiological model of morphological neuronal and glial plasticity in the adult hypothalamus. Front. Neuroendocrinol. 23:226. doi: 10.1006/frne.2001.0226

Thompson, R. A. (2016). "Early Attachment and Later Development: Familiar Questions, New Answers," in Handbook of Attachment: Theory, Research, and Clinical Applications, 3rd Edn, eds J. Cassidy and P. R. Shaver (New York, NY: Guildford Press), 155-179.

Toepfer, P., Heim, C., Entringer, S., Binder, E., Wadhwa, P., and Buss, C. (2017). Oxytocin pathways in the intergenerational transmission of maternal early life stress. Neurosci. Biobehav. Rev. 73, 293-308. doi: 10.1016/j.neubiorev.2016.12. 026

Tribollet, E., Goumaz, M., Raggenbass, M., and Dreifuss, J. J. (1991). Appearance and transient expression of vasopressin and oxytocin receptors in the rat brain. J. Recept. Res. 11, 333-346. doi: 10.3109/10799899109066412

Tronick, E., Als, H., Adamson, L., Wise, S., and Brazelton, T. B. (1978). The infant's response to entrapment between contradictory messages in face-toface interaction. J. Am. Acad. Child Psychiatry 17, 1-13. doi: 10.1016/s00027138(09)62273-1

Tsuji, S., Yuhi, T., Furuhara, K., Ohta, S., Shimizu, Y., and Higashida, H. (2015). Salivary oxytocin concentrations in seven boys with autism spectrum disorder received massage from their mothers: a pilot study. Front. Psychiatry 6:58. doi: $10.3389 /$ fpsyt.2015.00058

Uvnäs Moberg, K., Handlin, L., Kendall-Tackett, K., and Petersson, M. (2019). Oxytocin is a principal hormone that exerts part of its effects by active fragments. Med. Hypotheses 133:109394. doi: 10.1016/j.mehy.2019.10 9394

Uvnäs-Moberg, K. (2015). Oxytocin: The Biological Guide to Motherhood. London: Hale Publishing.

Uvnäs-Moberg, K., Arn, I., and Magnusson, D. (2005). The psychobiology of emotion: the role of the oxytocinergic system. Int. J. Behav. Med. 12, 59-65. doi: 10.1207/s15327558ijbm1202_3

Uvnäs-Moberg, K., Bruzelius, G., Alster, P., and Lundeberg, T. (1993). The antinociceptive effect of non-noxious sensory stimulation is mediated partly through oxytocinergic mechanisms. Acta Physiol. Scand. 149, 199-204. doi: 10.1111/j.1748-1716.1993.tb09612.x

Uvnäs-Moberg, K., Ekström-Bergström, A., Berg, M., Buckley, S., Pajalic, Z., Hadjigeorgiou, E., et al. (2019). Maternal plasma levels of oxytocin during physiological childbirth-A systematic review with implications for uterine contractions and central actions of oxytocin. BMC Pregnancy Childbirth 19:285. doi: 10.1186/s12884-019-2365-9 
Uvnäs-Moberg, K., Handlin, L., and Petersson, M. (2014). Self-soothing behaviors with particular reference to oxytocin release induced by nonnoxious sensory stimulation. Front. Psychol. 5:1529. doi: 10.3389/fpsyg.2014. 01529

van Ijzendoorn, M. H., and Sagi-Schwartz, A. (2008). Cross-Cultural Patterns of Attachment: Universal and Contextual Dimensions. In Handbook of attachment: Theory, research, and clinical applications, 2nd Edn. New York, NY: The Guilford Press, 880-905.

Velandia, M. (2012). Parent-Infant Skin-to-Skin Contact Studies. Department of Women's and Children's Health. Solna: Karolinska Institutet.

Vittner, D., McGrath, J., Robinson, J., Lawhon, G., Cusson, R., Eisenfeld, L., et al. (2018). Increase in oxytocin from skin-to-skin contact enhances development of parent-infant relationship. Biol. Res. Nurs. 20, 54-62. doi: 10. $1177 / 1099800417735633$

Voos, A. C., Pelphrey, K. A., and Kaiser, M. D. (2013). Autistic traits are associated with diminished neural response to affective touch. Soc. Cogn. Affect. Neurosci. 8, 378-386. doi: 10.1093/scan/nss009

Walker, S. C., Trotter, P. D., Swaney, W. T., Marshall, A., and McGlone, F. (2017). C-tactile afferents: Cutaneous mediators of oxytocin release during affiliative tactile interactions? Neuropeptides 64, 27-38. doi: 10.1016/j.npep.2017.01.001

Wang, P., Yang, H.-P., Tian, S., Wang, L., Wang, S. C., Zhang, F., et al. (2015). Oxytocin-secreting system: A major part of the neuroendocrine center regulating immunologic activity. J. Neuroimmunol. 289, 152-161. doi: 10.1016/ j.jneuroim.2015.11.001

Watanabe, T., Kuroda, M., Kuwabara, H., Aoki, Y., Iwashiro, N., Tatsunobu, N., et al. (2015). Clinical and neural effects of six-week administration of oxytocin on core symptoms of autism. Brain 138(Pt. 11), 3400-3412. doi: 10.1093/brain/ awv249

Wei, B., Tai, F., Liu, X., Ma, L., Yang, X., Jia, R., et al. (2013). Neonatal tactile stimulation alleviates the negative effects of neonatal isolation on novel object recognition, sociability and neuroendocrine levels in male adult mandarin voles (Microtus mandarinus). Physiol. Behav. 11, 14-22. doi: 10.1016/j.physbeh.2013. 02.005

Welch, M. G., and Ludwig, R. J. (2017). Calming cycle theory and the co-regulation of oxytocin. Psychodyn. Psychiatry 45, 519-540. doi: 10.1521/pdps.2017.45.4. 519
Williams, L. R., and Turner, P. R. (2020). Infant carrying as a tool to promote secure attachments in young mothers: Comparing intervention and control infants during the still-face paradigm. Infant Behav. Dev. 58:101413. doi: 10.1016/j. infbeh.2019.101413

Wolff, M. S. D., and Van IJzendoorn, M. H. (1997). Sensitivity and attachment: a meta-analysis on parental antecedents of infant attachment. Child Dev. 68, 571-591. doi: 10.1111/j.1467-8624.1997.tb04218.x

Woodhouse, S. S., Scott, J. R., Hepworth, A. D., and Cassidy, J. (2020). Secure base provision: a new approach to examining links between maternal caregiving and infant attachment. Child Dev. 91, e249-e265. doi: 10.1111/cdev.13224

Wright, B., and Edginton, E. (2016). Evidence-based parenting interventions to promote secure attachment: findings from a systematic review and meta-analysis. Glob. Pediatr. Health 3:2333794X16661888. doi: 10.1177/ $2333794 \times 16661888$

Yamasue, H. (2016). Promising evidence and remaining issues regarding the clinical application of oxytocin in autism spectrum disorders. Psychiatry Clin. Neurosci. 70, 89-99. doi: 10.1111/pcn.12364

Yokoyama, Y., Ueda, T., Irahara, M., and Aono, T. (1994). Releases of oxytocin and prolactin during breast massage and suckling in puerperal women. Eur. J. Obstet. Gynecol. Reprod. Biol. 53, 17-20. doi: 10.1016/0028-2243(94) 90131-7

Zheng, W., Zhu, X.-M., Zhang, Q.-E., Yang, X.-H., Cai, D.-B., Li, L., et al. (2019). Adjunctive intranasal oxytocin for schizophrenia: A meta-analysis of randomized, double-blind, placebo-controlled trials. Schizophr. Res. 206, 13-20. doi: 10.1016/j.schres.2018.12.007

Conflict of Interest: The author declares that the research was conducted in the absence of any commercial or financial relationships that could be construed as a potential conflict of interest.

Copyright (c) 2021 Norholt. This is an open-access article distributed under the terms of the Creative Commons Attribution License (CC BY). The use, distribution or reproduction in other forums is permitted, provided the original author(s) and the copyright owner(s) are credited and that the original publication in this journal is cited, in accordance with accepted academic practice. No use, distribution or reproduction is permitted which does not comply with these terms. 